\title{
As relações intersetoriais do setor energético na economia brasileira: uma abordagem insumo-produto
}

\author{
Marco Antonio Montoya* \\ Cássia Aparecida Pasqual (in memorian)* \\ Ricardo Luis Lopes**** \\ Joaquim José Martins Guilhoto****
}

\section{Resumo}

Este artigo avalia as relações intersetoriais do setor energético na economia brasileira, utilizando a matriz insumo-produto estimada para 2009. Verificou-se que o setor energético constitui-se no principal setor-chave da economia, estimula de forma abrangente o crescimento econômico e seus estímulos destacam-se na geração de produção, empregos e salários. As simulações sobre o setor energético mostraram que os setores serviços são os principais canais de transmissão dos impactos de um maior consumo de energia na economia brasileira. Trata-se, portanto, de um setor estratégico para o crescimento econômico que precisa de um fluxo contínuo de investimentos para incrementar sua produção.

Palavras-chave: Setor energético. Crescimento econômico. Requerimentos de energia. Insumo-produto.

" Professor titular da Faculdade de Ciências Econômicas, Administrativas e Contábeis da Universidade de Passo Fundo (Feac-UPF). E-mail: montoya@upf.br

** Professora da Faculdade de Ciências Econômicas, Administrativas e Contábeis da Universidade de Passo Fundo (Feac-UPF). E-mail: cpasqual@upf.br

**** Professor da Universidade Estadual de Maringá (UEM). E-mail: rllopes@uem.br

**** Professor titular da Faculdade de Economia e Administração da Universidade de São Paulo (FEA-USP). Adjunct professor do Regional Economics Applications Laboratory (Real) da University of Illinois (EUA). Pesquisador do CNPq. E-mail: guilhoto@usp.br

http://dx.doi.org/10.5335/rtee.v21i44.5353

Submissão: 20/11/2014. Aceite: 13/05/2015. 


\section{Introdução}

Previsões sobre o crescimento da economia mundial apontam que, até o ano de 2035 , o produto interno bruto (PIB) crescerá a uma taxa de $3,2 \%$ ao ano, passando de 63,13 trilhões de dólares em 2007 para 153,66 trilhões de dólares em 2035, ou seja, o tamanho do mercado mundial aumentará em 243,40\%. Sem dúvida, esse crescimento terá um relevante papel no aumento da demanda de energia dado sua vital importância para o desenvolvimento de qualquer sistema econômico. No Brasil, o Balanço Energético Nacional (BEN) informa que o consumo de energia em 2009 atingiu 220.711 milhões de tep. Assim, se considerarmos as projeções da International Energy Outlook (IEO) (2010) de um crescimento no consumo de energia de $2,4 \%$ ao ano (no período de 2007 a 2035), espera-se que a demanda de energia do país aumente em 185,79\% no período, passando de 220.711 milhões para 410,060 milhões de tep em 2035 (BERS, 2011).

Questões sobre se o Brasil está preparado para atender a essa nova demanda de energia ficam em evidência já que a pressão sobre a maior produção desse insumo, por parte das diversas indústrias, intensificar-se-á nos próximos anos, ao mesmo tempo em que o consumo de energia das famílias aumentará por conta do crescimento da população e, principalmente, da renda. Certamente, para que a produção de energia não seja o ponto de estrangulamento do crescimento econômico, será preciso definir com clareza no setor energético as metas de investimento para a produção de energia bem como o papel estratégico que desempenhará no crescimento econômico nacional.

Para isso, torna-se de suma importância conhecer a abrangência da interdependência setorial do setor energético e sua capacidade de estimular o crescimento na economia. O modelo insumo-produto possibilita retratar essas relações em diferentes níveis de complexidade. Ele é um instrumento adequado para avaliar as relações setoriais da produção e do consumo de energia no país em virtude de incorporar o setor energético no sistema econômico.

Diante desse panorama, e considerando as perspectivas de aumento do consumo de energia nos próximos anos, este estudo tem como objetivo avaliar a importância relativa do setor energético para o crescimento da economia brasileira. Com esse fim, inicialmente, caracterizam-se as compras e vendas do setor por origem e destino, identificam-se os setores que mais pressionam o consumo de energia devido ao requerimento de energia, bem como se salienta a relevância do setor energético nos encadeamentos setoriais e nos multiplicadores econômicos. Em 
seguida, avaliam-se os impactos econômicos do setor decorrentes das previsões de crescimento do consumo de energia no país para os próximos anos. Com isso, espera-se fornecer subsídios que permitam, por um lado, estabelecer prioridades nos investimentos destinados ao abastecimento de energia e, por outro, entender a abrangência das relações do setor energético com os diferentes setores econômicos determinantes do crescimento econômico do país.

O presente artigo está dividido da seguinte maneira: a seção 2 apresenta alguns aspectos da produção de energia na matriz energética nacional bem como salienta estudos relevantes sobre o uso setorial de energia e suas implicações ambientais; na seção 3, é às apresentado o processo metodológico de análise, a estrutura matemática para gerar os indicadores e a base de dados utilizada; a seção 4 avalia a relevância do setor energético para o crescimento da economia brasileira; na seção 5, avaliam-se os impactos econômicos na produção, emprego e salários provenientes do maior consumo de energia no país previstos até 2015; na última seção, são apresentadas as principais conclusões obtidas no decorrer da análise.

\section{$2 \mathrm{O}$ setor energético brasileiro}

Nos últimos anos, o mundo mudou de maneira significativa, dando maior importância aos riscos e incertezas da degradação ambiental. Tendências no uso de energia mais limpa foram introduzidas no desenvolvimento sustentável, embora, na economia brasileira ainda predomine a produção e o consumo de energia não renovável. Isto é, conforme a Tabela 1, na composição da produção de energia primária nacional de 2009 a 2011, em média, as fontes de energia não renováveis respondem por $53,30 \%$, ou 133.241 mil tep, e as fontes renováveis por $46,70 \%$, ou 116.687 mil tep.

Na produção por fontes de energia, o petróleo responde por $42,20 \%$, ou 105.484 mil tep, da energia primária do país. Os produtos da cana-de-açúcar ocupam a segunda posição com uma produção de 45.633 mil tep, ou $18,27 \%$, seguidos pela energia hidráulica, com 35.048 mil tep, ou 14,02\%, pela lenha, com 25.643 mil tep, ou $10,26 \%$, e por outras fontes primárias, com 10.363 mil tep, ou 4,14\%. Trata-se, portanto, de uma matriz energética poluidora, mas que oferece, no entanto, pela participação das fontes de energia renováveis, potencial para a redução de emissões de gases de efeito estufa por meio do uso de combustíveis menos poluidores e renováveis. Nesse sentido, note-se que a energia hidráulica no Brasil responde por $30,04 \%$ das fontes renováveis, enquanto que no mundo a participação média da energia hidráulica atinge somente 16\% (BRASIL, 2013). 
Tabela 1 - Produção de fontes de energia primária no Brasil no período de 2009 a 2011. Em milhões e percentuais

\begin{tabular}{l|r|r|r|r|r|r|r|r}
\hline \multirow{2}{*}{ Fontes de energia primária } & \multicolumn{2}{|c|}{2009} & \multicolumn{2}{c|}{2010} & \multicolumn{2}{c|}{2011} & \multicolumn{2}{c}{ Média do período } \\
\cline { 2 - 9 } & $\begin{array}{l}\text { Produção } \\
\text { mil tep }\end{array}$ & $\%$ & $\begin{array}{c}\text { Produção } \\
\text { mil tep }\end{array}$ & $\%$ & $\begin{array}{c}\text { Produção } \\
\text { mil tep }\end{array}$ & $\%$ & $\begin{array}{c}\text { Produção } \\
\text { mil tep }\end{array}$ & $\%$ \\
\hline Petróleo & 100.918 & 42,07 & 106.559 & 42,09 & 108.976 & 42,45 & 105.484 & 42,20 \\
Gás natural & 20.983 & 8,75 & 22.771 & 8,99 & 23.888 & 9,30 & 22.547 & 9,02 \\
Carvão vapor & 2.080 & 0,87 & 2.104 & 0,83 & 2.104 & 0,82 & 2.096 & 0,84 \\
Urânio u ${ }_{3} \mathrm{O}_{8}$ & 3.428 & 1,43 & 1.767 & 0,70 & 4.143 & 1,61 & 3.113 & 1,25 \\
\hline Energia não renovável total & 127.409 & 53,12 & 133.201 & 52,61 & 139.112 & 54,18 & 133.241 & 53,30 \\
\hline Energia hidráulica & 33.625 & 14,02 & 34.683 & 13,70 & 36.837 & 14,35 & 35.048 & 14,02 \\
Lenha & 24.609 & 10,26 & 25.997 & 10,27 & 26.322 & 10,25 & 25.643 & 10,26 \\
Produtos da cana & 44.775 & 18,67 & 48.852 & 19,30 & 43.270 & 16,85 & 45.633 & 18,27 \\
Outras fontes primárias & 9.450 & 3,94 & 10.440 & 4,12 & 11.200 & 4,36 & 10.363 & 4,14 \\
\hline Energia renovável total & 112.460 & 46,88 & 119.973 & 47,39 & 117.628 & 45,82 & 116.687 & 46,70 \\
\hline Energia primária total & 239.869 & 100,00 & 253.174 & 100,00 & 256.740 & 100,00 & 249.927 & 100,00 \\
\hline
\end{tabular}

Fonte: elaboração dos autores com base no Balanço Energético Nacional - (EPE, 2012).

Apesar da presença majoritária das fontes não renováveis de energia, a matriz energética brasileira é uma das mais limpas do mundo, com forte presença de fontes renováveis de energia (BRASIL, 2013). Enquanto no Brasil a energia renovável tem $46,70 \%$ de participação, no mundo e nos países ricos esse percentual não passa de $13 \%$ e $8 \%$, respectivamente. Pelo lado das emissões, enquanto o país emite 1,4 tonelada de dióxido de carbono $\left(\mathrm{tCO}_{2}\right)$ por tonelada equivalente de petróleo (tep), no mundo esse indicador é de 2,4 $\mathrm{tCO}_{2}$ /tep. Em alguns países com forte presença de fontes fósseis (óleo, gás e carvão mineral) em suas matrizes energéticas esse indicador passa de $3 \mathrm{tCO}_{2}$ /tep.

Considerando que a produção de energia deverá crescer à medida que cresce a economia brasileira, sua indisponibilidade pode produzir efeitos econômicos adversos. Assim, diversos estudos que utilizam modelos insumo-produto híbridos estão sendo desenvolvidos no país para entender a disponibilidade e o uso setorial de energia com suas implicações ambientais. Dentre eles, podemos destacar os trabalhos de Hilgemberg e Guilhoto (2006), Carneiro, Figueiredo e Araújo Júnior (2009), Mattos (2010), Firme e Perobelli (2012). Entretanto, esses estudos apresentam 
resultados muito agregados em função da necessidade de compatibilizar os setores da matriz de insumo-produto (MIP) e do BEN. Já os trabalhos de Montoya, Lopes e Guilhoto (2013) e de Montoya et al. (2013), que desagregam o BEN em 56 setores similares aos que apresenta a MIP do Brasil, superam essa dificuldade. Contudo, nesta pesquisa não será utilizado o modelo híbrido, mas sim o modelo insumo-produto clássico, uma vez que estamos interessados em analisar de que maneira o setor energético insere-se no crescimento econômico nacional.

\section{Metodologia}

Para analisar o setor energético do Brasil, torna-se necessário, sob a ótica de um modelo de insumo-produto, identificar e quantificar suas relações com os demais setores da economia. Com esse fim, a seguir, apresenta-se, o modelo teórico insumo-produto que evidencia o setor energético dentre os diversos setores do sistema econômico, os índices econômicos calculados para sua caracterização bem como a organização e o tratamento da base de dados utilizada. A formalização matemática dos indicadores estimados para esta pesquisa foi extraída de Guilhoto (2011), Fochezatto e Grando (2011), Montoya et al. (2011), Finamore e Montoya (2013).

\section{$3.1 \mathrm{O}$ modelo insumo-produto}

A matriz de insumo-produto, desenvolvida por Leontief (1951 e 1983), constitui-se em um quadro estatístico de dupla entrada que registra os insumos utilizados pelas distintas atividades econômicas e o destino das produções, possibilitando a percepção da interdependência setorial.

No modelo aberto insumo-produto, a equação (1) mostra que a demanda total do produto do setor $i$ é igual à soma da demanda intermediária e da demanda final. A equação (2) mostra que a produção bruta do setor $j$ é igual ao consumo intermediário mais as contribuições dos fatores de produção (valor adicionado). Finalmente, a equação (3) mostra a condição de equilíbrio entre a oferta e a demanda para cada um dos setores produtivos da economia.

$$
X_{i}=\sum_{j=1}^{n} x_{i j}+\sum_{k=1}^{n} Y_{i k}
$$

Demanda total $=$ demanda intermediária + demanda final 


$$
X_{j}=\sum_{i=1}^{n} x_{i j}+\sum_{r=1}^{n} V_{r j}
$$

Oferta total $=$ consumo intermediário + fatores primários (valor adicionado)

$$
\sum_{j=1}^{n} x_{i j}+\sum_{k=1}^{n} Y_{i k}=\sum_{i=1}^{n} x_{i j}+\sum_{r=1}^{n} V_{r j}
$$

Demanda total $=$ oferta total

Em que $X_{i}$ e $X_{j}$ são valores da produção do setor $i$ (linha) e $j$ (coluna); $x_{i j}$ é consumo intermediário do setor $j$ de produtos oriundos do setor $i$; $Y_{i k}$ é a demanda final dos produtos $i$ por parte do componente $k ; V_{k j}$ é o fator de produção $k$ demandado pelo setor $j$. Desde que o valor da demanda total seja igual ao valor da oferta total de produtos $\left(X_{i}=X_{j}\right)$, o modelo insumo-produto será consistente.

Em termos agregados, a soma do valor adicionado dos setores fornece a renda agregada da economia e a soma da demanda final dos setores resulta no dispêndio agregado. Aplicando essa identidade para o conjunto dos setores, obtém-se:

$$
\sum_{i=1}^{n}\left(\sum_{k=1}^{n} Y_{i k}\right)=\sum_{j=1}^{n}\left(\sum_{r=1}^{n} V_{r j}\right)
$$

Renda agregada $=$ dispêndio agregado

No modelo insumo-produto, supõe-se que os coeficientes de produção são fixos, ou seja, os requerimentos de insumos intermediários têm uma participação fixa em relação à produção bruta dos setores. Os coeficientes técnicos $\left(a_{i j}\right)$ representam a quantidade do produto do setor $i$ requerida para produzir uma unidade do produto do setor $j$. Assim:

$$
a_{i j}=\frac{x_{i j}}{X_{j}} \quad \text { ou } x_{i j}=a_{i j} X_{j}
$$

Os requerimentos de fatores de produção também têm uma relação fixa com respeito à produção total do setor $j$. Os coeficientes técnicos $\left(d_{r j}\right)$ representam a quantidade do fator primário $r$ requerida para produzir uma unidade de produto do setor $j$. Assim:

$$
d_{r j}=\frac{V_{r j}}{X_{j}} \quad \text { ou } \quad V_{r j}=d_{r j} X_{j}
$$


Substituindo as equações (5) e (6) na equação (2), obtém-se a equação (7), que dividida por $X_{j}$, resulta na equação (8).

$$
\begin{gathered}
X_{j}=\sum_{i=1}^{n} a_{i j} X_{j}+\sum_{r=1}^{n} d_{r j} X_{j} \\
\sum_{i=1}^{n} a_{i j}+\sum_{r=1}^{n} d_{r j}=1
\end{gathered}
$$
Substituindo a equação (5) na equação (1), e fazendo $\sum_{k=1}^{n} Y_{i k}=Y_{i}$, obtém-se o
sistema de equações (9).

$$
X_{i}-\sum_{j=1}^{n} a_{i j} X_{i}=Y_{i}
$$

A solução do modelo aberto de Leontief para a produção setorial passa a ser expresso matricialmente (10), cuja solução é dada pela equação (11).

$$
\begin{gathered}
X-A X=Y \\
X=(I-A)^{-1} Y
\end{gathered}
$$

Os coeficientes da matriz inversa $(I-A)^{-1} Y$ são chamados de requerimentos totais de produção, ou seja, os requerimentos diretos e indiretos de produção. Eles indicam as mudanças na produção setorial necessárias para atender a uma determinada variação da demanda final. Note-se que a demanda final do modelo é exógena, o que permite que se analisem de forma sistêmica o perfil da estrutura de transações, os efeitos multiplicadores decorrentes da demanda final, diferentes tipos de problemas que envolvem programas de investimentos, aumento do consumo, tributação, mudança tecnológica, etc.

Além dos requerimentos de produção, é possível definir os requerimentos de fatores primários. Como mostra a equação (6), os fatores primários estabelecem uma relação fixa com a produção bruta dos setores. O total de fatores primários usados em cada setor pode ser expresso pela equação (12), que, na forma matricial compacta, pode ser representada pela equação (13).

$$
\begin{gathered}
V_{j}=\sum_{r=1}^{n} d_{r j} X_{j} \\
V=D X
\end{gathered}
$$


Nela, $V$ é um vetor de fatores primários de $r$ componentes, e $D$ é uma matriz $(r \times j)$ de coeficientes de fatores primários. Substituindo a equação (11) na equação (13), obtém-se a equação (14):

$$
V=D(I-A)^{-1} Y
$$

A matriz $D(I-A)^{-1}$ é chamada de matriz de requerimentos diretos e indiretos de fatores primários. Seus coeficientes medem o impacto de um aumento da demanda final sobre os componentes do valor adicionado ou dos fatores primários. Com isso, é possível determinar também os efeitos multiplicadores de variações na demanda final de cada atividade produtiva sobre os componentes do valor adicionado de cada setor.

O modelo insumo-produto, além de analisar as transações intersetoriais de insumos permite também incorporar o consumo das famílias como uma variável endógena (modelo fechado). Com isso, é possível não somente avaliar os efeitos diretos e indiretos, mas também o efeito induzido ou denominado também efeito-renda. A nova solução terá um novo vetor de demanda final, sem o vetor do consumo das famílias, uma nova matriz de coeficientes intermediários, com uma linha e uma coluna a mais e, portanto, uma nova matriz inversa de Leontief.

Operacionalmente, isso consiste, inicialmente, em subtrair da matriz $(I-A)$ a matriz resultante da multiplicação dos coeficientes de consumo das famílias $\left(c_{j}\right)$, pelos coeficientes do valor adicionado $\left(v_{i}\right)$ e, logo, calcular a inversa dessa matriz. Assim, a solução do modelo insumo-produto fechado é dada pelas equações (15) e (16).

$$
X=\left[(I-A)-c_{j} v_{i}\right]^{-1} Y
$$

$$
\begin{array}{r}
\text { Sendo } c_{j}=\frac{c_{i k}}{\sum_{i=1}^{n}\left(\sum_{r=1}^{n} V_{r j}\right)} \quad \begin{array}{c}
\text { e } \quad v_{i}=\frac{V_{j}}{X_{i}} \\
X=D\left[(I-A)-c_{j} v_{i}\right]^{-1} Y
\end{array}
\end{array}
$$

Os valores dos multiplicadores dessas matrizes sempre serão superiores aos da matriz do modelo aberto. Isso ocorre porque na matriz $A$ foi incorporado o consumo e a renda das famílias. 


\subsection{Requerimentos setoriais de energia}

Para recuperar os requerimentos de energia dos requerimentos totais de produção, é necessário encontrar os coeficientes técnicos do consumo de energia $\left(h_{i}\right)$, que representa quantidade de energia $\left(H_{i}\right)$ requerida para produzir uma unidade do produto do setor $j$.

$$
h_{i}=\frac{H_{i}}{X_{j}}
$$

Logo, os coeficientes $\delta$ constituem a matriz dos requerimentos diretos de energia e os coeficientes $\varphi$ representam a matriz de requerimentos totais

$$
\begin{gathered}
\delta=\hat{h}_{i} A \\
\varphi=\hat{h}_{i}(I-A)^{-1}
\end{gathered}
$$

A matriz dos requerimentos indiretos de energia $(\lambda)$ é obtida pela diferença da matriz de requerimentos totais $(\varphi)$ e da matriz de requerimentos diretos $(\delta)$.

$$
\lambda=\hat{h}_{i}(I-A)^{-1}-\hat{h}_{i} A
$$

\subsection{Encadeamentos setoriais}

Os índices de ligações de Rasmussen (1956) e Hirschman (1958) permitem identificar os setores que teriam maior poder de encadeamento dentro da economia. Os índices de ligações para trás dizem-nos o quanto um setor demanda dos outros, e os índices de ligações para frente, dizem-nos o quanto esse setor é demandado pelos outros, valores maiores que 1 indicam setores acima da média e são, portanto, setores-chave para o crescimento da economia. A fim de complementar esses índices, pode-se associar a cada um deles os coeficientes de dispersão de Bulmer (1982). Um valor baixo de dispersão significa que o impacto de uma variação da produção em um dado setor estimularia os outros setores de uma maneira uniforme, enquanto que um valor alto de dispersão significaria que o estímulo seria concentrado em poucos setores.

Desse modo, a partir da equação (11), definimos $b_{i j}$ como sendo um elemento da matriz inversa de Leontief $(I-A)^{-1}$ ou simbolizado também como $B ; B^{*}$ como sendo a média de todos os elementos de $B$ e $B_{*_{j}}, B_{i^{*}}$ como sendo, respectivamente, a soma de uma coluna e de uma linha típica de $B$. Temos então nas equações (21) e 
(22) o índice de ligação e de dispersão para trás e, nas equações (23) e (24) o índice de ligação e de dispersão para frente, respectivamente.

$$
\begin{gathered}
U_{j}=\left[B_{*_{j}} / n\right] / B^{*} \\
u_{j}=\frac{\sqrt{\frac{\sum_{i}^{n}\left(b_{i j}-B_{*_{j}} / n\right)^{2}}{(n-1)}}}{B_{*_{j}} / n} \\
U_{i}=\left[B_{i^{*}} / n\right] / B^{*} \\
u_{i}=\frac{\sqrt{\frac{\sum_{i}^{n}\left(b_{i j}-B_{*_{j}} / n\right)^{2}}{(n-1)}}}{B_{i^{*}} / n}
\end{gathered}
$$

\subsection{Multiplicadores tipo I}

Quando o efeito de multiplicação restringe-se somente à demanda de insumos intermediários, eles são chamados de multiplicadores tipo I. A partir dos coeficientes diretos apresentados na equação (6) e dos coeficientes da matriz inversa $(I-A)^{-1}$, é possível estimar, para cada setor da economia, o quanto é gerado direta e indiretamente de emprego, importações, impostos, salários, valor adicionado, etc., para cada unidade monetária produzida para a demanda final. Ou seja:

$$
G V_{J}=\hat{d}_{r}(I-A)^{-1}
$$

Em que $G V_{J}$ é o impacto total, direto e indireto, sobre a variável em questão e; $d_{r}$ é o coeficiente direto diagonalizado da variável em questão.

A divisão dos geradores pelo respectivo coeficiente direto do insumo primário gera os multiplicadores, que indicam o quanto é gerado, direta e indiretamente, por exemplo, de empregos, impostos, salários, etc. Então, o multiplicador do i-ésimo setor será dado por:

$$
M V_{i}=\frac{G V_{i}}{d_{i}}
$$


Em que $M V_{i}$ representa o multiplicador da variável em questão.

Por sua vez, o multiplicador de produção que indica o quanto se produz para cada unidade monetária gasta na demanda final é definido na equação (27) como sendo a soma das colunas do $j$-ésimo setor $\left(b_{i j}\right)$ da matriz inversa $(I-A)^{-1}$.

$$
M P_{J}=\sum_{i=1}^{n} b_{i j}
$$

\subsection{Multiplicadores tipo II}

Quando a demanda das famílias é endogenizada no sistema do modelo insumo-produto, os efeitos multiplicadores captam o efeito induzido da renda, pelo qual são denominados multiplicadores tipo II. Eles indicam que o aumento do nível de atividade e do emprego leva a uma elevação da renda disponível, tanto para os trabalhadores quanto para os empresários. Esse aumento de renda traduz-se em um novo aumento na demanda de bens, desta vez ocasionada pelo consumo final das famílias, que gerará um adicional de produção não captado pelo multiplicador tipo I.

As equações (28), (29) e (30) sintetizam esse processo de estimação.

$$
\begin{gathered}
G^{*} V_{J}=\widehat{d}_{r}\left[(I-A)-c_{j} v_{i}\right]^{-1} \\
M^{*} V_{i}=\frac{G^{*} V_{i}}{d_{i}} \\
M P_{j}^{*}=\sum_{i=1}^{n} b_{i j}^{*}
\end{gathered}
$$

\subsection{Efeito-renda}

O efeito renda ou efeito induzido no sistema econômico é estabelecido para cada insumo primário pela diferença dos multiplicadores tipos II e I. Na equação (31), eles indicam o quanto a mais se produz em função do aumento da renda na economia que, por sua vez, ocasiona aumento no consumo das famílias.

$$
E R=M^{*} V_{i}-M V_{i}
$$




\subsection{Simulações de impacto}

Para avaliar os impactos do setor energético sobre a economia brasileira assumiu-se uma taxa de crescimento em sua demanda final. Para tanto, em uma economia com $n$ setores, seja $Y^{r}$ o vetor-coluna cujos elementos são igual a zero, exceto para o setor energético que teve o acréscimo de 15,62\%. Logo, a nova demanda final será:

$$
\Delta Y=Y+Y^{r}
$$

Os impactos sobre a produção e sobre cada insumo primário podem ser obtidos pelas equações (33) e (34), respectivamente.

$$
\begin{gathered}
\Delta X=\left[(I-A)-c_{j} v_{i}\right]^{-1} \Delta Y \\
\Delta X=D\left[(I-A)-c_{j} v_{i}\right]^{-1} \Delta Y
\end{gathered}
$$

Os resultados líquidos $\left(X^{r}\right)$ dessas simulações podem ser encontrados pela diferença dos valores estimados e valores originais da produção e dos insumos primários, $X^{r}=\Delta X-X$, alternativamente.

\subsection{Fonte e natureza dos dados}

A MIP mais recente publicada pelo Instituto Brasileiro de Geografia e Estatística (IBGE) refere-se ao ano de 2005. Assim, com fins de estabelecer uma visão mais atualizada do setor energético brasileiro, os dados utilizados foram extraídos da matriz insumo-produto do Brasil de 2009 estimada por Guilhoto e Sesso Filho (2005, 2010). As informações da MIP apresentam 56 setores e 110 produtos.

A agregação das informações levou em consideração a Classificação Nacional de Atividades Econômicas (2.0) do IBGE bem como o grau de homogeneidade das atividades de cada setor. Como resultado, quatro setores passaram a compor o setor energético (Petróleo e gás natural, Refino de petróleo e coque, Álcool e Serviços de utilidade pública - SIUP), e dez produtos passaram a constituir o produto Energia (Petróleo e gás natural, Carvão mineral, Gás liquefeito de petróleo, Gasolina automotiva, Gasoálcool, Óleo combustível, Óleo diesel, Outros produtos do refino de petróleo e coque, Álcool e SIUP, que incorpora a eletricidade). A agregação desses setores e produtos permitiu obter uma matriz de 53 por 53 setores, cujos 
valores estão a custo de fatores e a preços de mercado, em milhões de reais, e adota a tecnologia setor versus setor, baseada na indústria.

\section{$4 \mathrm{O}$ setor energético e suas relações intersetoriais para o crescimento econômico}

Um dos propósitos da análise de insumo-produto é o esclarecimento das relações setoriais que se estabelecem com o comércio, isso porque com a caracterização da interdependência comercial é possível estabelecer alguns parâmetros sobre a dimensão econômica dos mercados e as situações mais prováveis da demanda potencial de produtos energéticos. Nesse sentido, a seguir, são apresentados os diversos resultados que salientam a importância relativa do setor energético para o crescimento da economia brasileira.

\subsection{Dimensão econômica do setor energético}

As transações entre os setores do país na tabela insumo-produto mostram as demandas intermediárias por insumos e as demandas finais por produtos. Do ponto de vista do Valor Bruto da Produção (VBP), verifica-se que o setor energético, para o ano de 2009, contribui para a economia brasileira com 7,75\% (ou 424.832 milhões de reais) e, do ponto de vista do valor adicionado ou PIB, sua contribuição relativa é de somente $5,54 \%$ (ou 154.770 milhões de reais).

Com base nesses fatos, pode-se argumentar que a oportunidade relacionada à maior geração de renda via aumento da demanda de produtos e serviços parece substancialmente maior para outros setores da economia do que para o setor energético. Entretanto, é necessário, para entender melhor a inserção estratégica do setor na economia, avaliar sua estrutura de compras e vendas setoriais, uma vez que, se faltar energia para o sistema produtivo, a maior renda dos outros setores poderá não se concretizar.

Nesse sentido, a estrutura de transações do setor energético, resumidas no Gráfico 1, mostra que $69,56 \%$ (ou 295.495 milhões de reais) de suas vendas são destinadas para o consumo intermediário de diversos setores do país na forma de insumos e 30,44\% (ou 129.337 milhões de reais) são destinadas como produtos para os componentes do consumo final. 
Gráfico 1 - Participação insumo-produto do setor energético nos fluxos setoriais na demanda intermediária e na demanda final

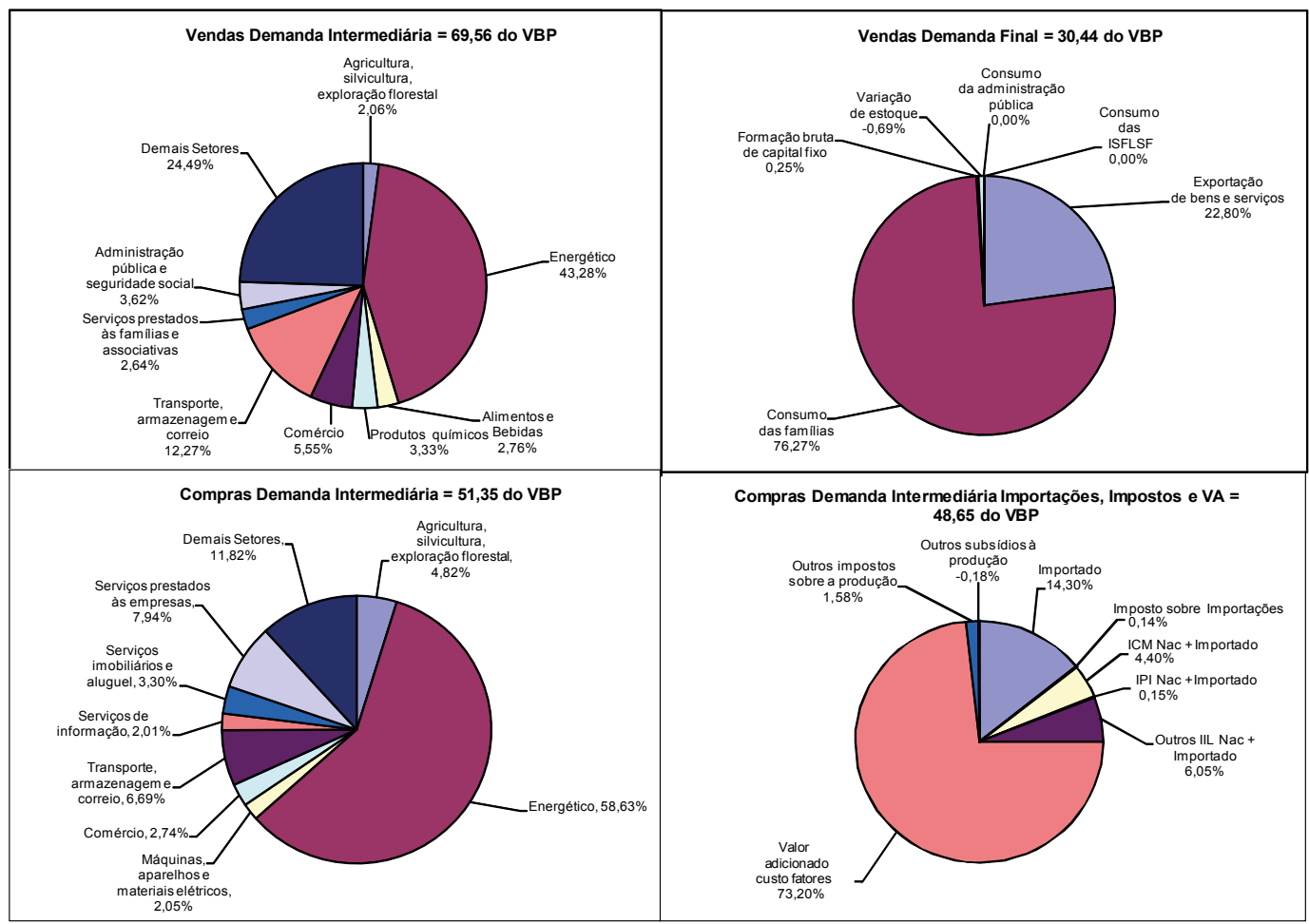

Fonte: elaboração dos autores.

Nota: nas vendas e compras de produtos nacionais da demanda intermediária, somente constam de forma desagregada os setores com participações acima de $2 \%$.

Em particular, no lado das vendas na demanda intermediária, o setor energético (com 43,28\% ou 127.890 milhões de reais) destaca-se como o maior consumidor de energia do país, seguido de longe, principalmente, pelo setor transporte, armazenagem e correio (com $12,27 \%$ ou 36.263 milhões de reais) e pelo Comércio (com $5,55 \%$ ou 16.387 milhões de reais). Note-se que, embora $43,28 \%$ da energia sejam consumidos pelo próprio setor energético no seu processo de refino e transformação, os restantes $56,72 \%$ do total de energia são destinados de forma pulverizada para as diversas cadeias produtivas do país. Assim, pode-se afirmar, pelo montante destinado aos diversos setores produtivos da demanda intermediária, a importância relativa do setor energético como fornecedor de insumos para a produção.

No lado das vendas na demanda final, destaca-se, por um lado, o consumo das famílias $(76,27 \%)$ como um componente importante que pressionará de forma 
significativa a produção de energia à medida que se incremente a renda familiar do país e, por outro, as exportações $(22,80 \%)$ com um peso relevante de energia canalizado para o mercado internacional.

No lado da demanda intermediária, as informações das compras que o setor energético faz para desenvolver suas atividades mostram que $51,35 \%$ (ou 218.132 milhões de reais) de seus insumos são comprados no país, sendo que, desse total, o mesmo setor se autoabastece com 58,63\% (ou 127.890 milhões de reais), seguido de longe pelo setor Serviços prestados às empresas com 7,94\% (ou 17.315 milhões de reais) e pelo setor transporte, armazenagem e correio com 6,69\% (ou 14.601milhões de reais) dos insumos. Nota-se também que o país apresenta uma dependência significativa por insumo de origem externa, já que 14,35\% (ou 29.661milhões de reais) dos insumos que o setor utiliza são importados. As remunerações salariais, contribuições e rendimentos contidos no valor adicionado a custo de fatores mostram uma participação de $73,20 \%$ (ou 151.862 milhões de reais).

Pelo conjunto de informações sobre a dimensão econômica setorial bem como dos fluxos insumo-produto, pode-se afirmar, em um primeiro momento, ainda que o setor energético tenha uma participação pequena no VBP e no PIB nacional, que a importância relativa do setor firma-se no fornecimento de insumos para as indústrias e de produtos para o consumo final.

\subsection{Requerimentos setoriais de energia na economia brasileira}

Dada a característica do setor energético como fornecedor de energia, a seguir, avaliam-se os requerimentos setoriais de energia em unidades monetárias com o objetivo de identificar os setores que mais pressionam a produção de energia para atender a um eventual aumento na demanda final. 


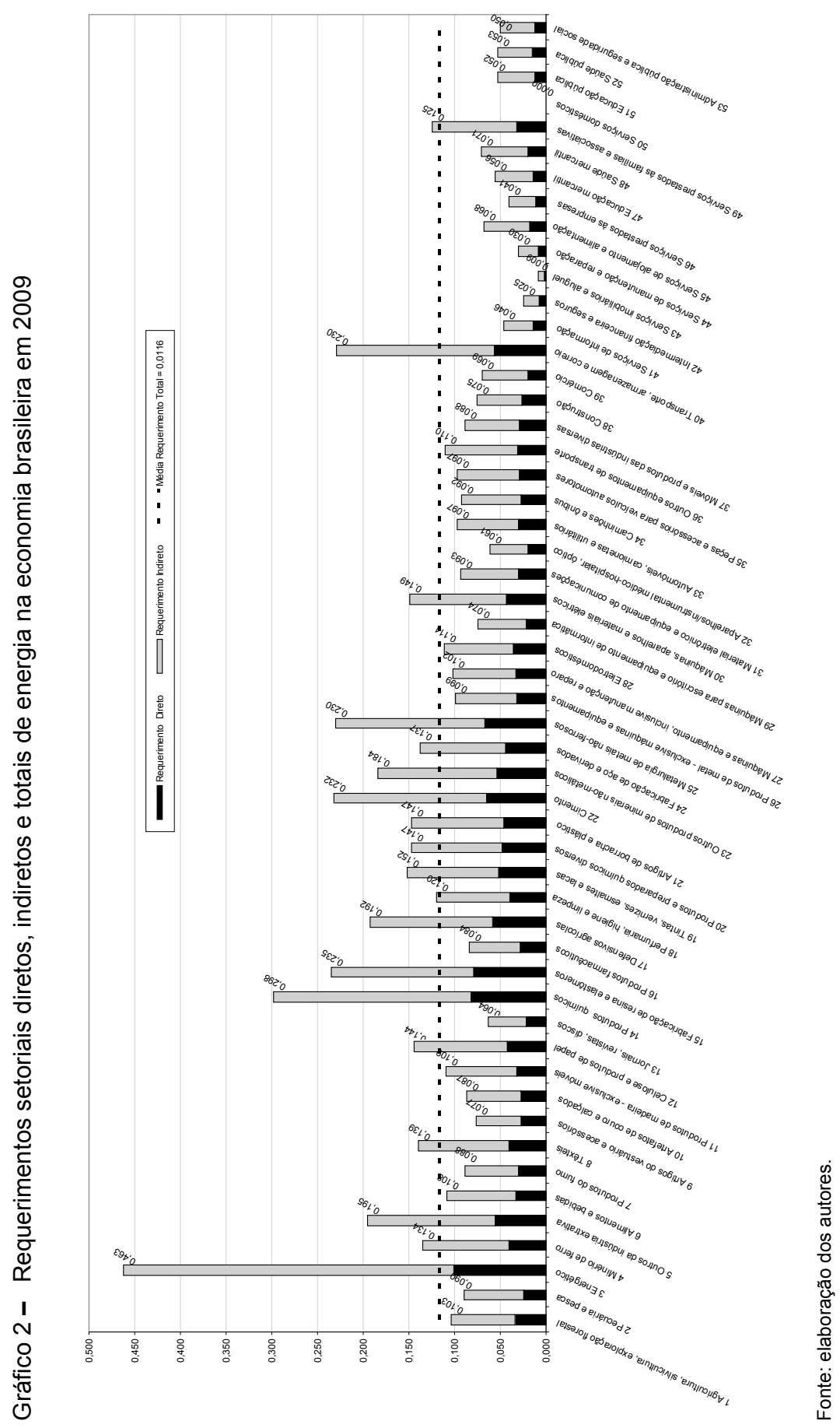

Teoria e Evidência Econômica - Ano 21, n. 44, p. 36-75, jan./jun. 2015 
As informações do Gráfico 2 mostram os requerimentos diretos, indiretos e totais de energia de cada setor da economia brasileira. De modo geral, observa-se que existem setores mais intensivos e menos intensivos no uso de energia. Para diferenciá-los, podemos estabelecer como parâmetro os dez maiores requerimentos totais ou os requerimentos acima da média nacional. Isso porque o aumento da demanda final de um setor relevante forçará um aumento relativamente mais forte nos demais setores e, portanto, um aumento ainda maior no consumo de energia.

Nesse sentido, considerando que a média de requerimentos totais de energia do país é de 0,116 , destacam-se entre os dez setores com maiores requerimentos o próprio setor energético $(0,100)$, o setor produtos químicos $(0,082)$, o setor fabricação de resina e elastômeros $(0,080)$, o setor metalurgia de metais não ferrosos $(0,067)$, setor Cimento (0,065), o setor Defensivos agrícolas $(0,059)$, o setor transporte, armazenagem e correio $(0,057)$, o setor outros da indústria extrativa $(0,056)$, o setor outros produtos de minerais não metálicos $(0,054)$ e o setor Tintas, vernizes, esmaltes e lacas $(0,052)$.

Por exemplo, o setor energético, que utiliza abundantes fontes de energia primária para produzir combustível óleo diesel, gasolina, álcool, eletricidade, etc., constitui-se, na economia brasileira, como o setor que consome o maior volume de energia por unidade de produção para satisfazer o aumento da demanda final. Isto é, um aumento na demanda final do setor de energético em um milhão de reais, causará um aumento total de 0,116 milhões de reais na produção de energia, o que equivale a $R \$ 116.000,00$ adicionais de consumo de energia. Fica evidente, portanto, que, ocorrendo o crescimento da produção em qualquer desses setores relevantes identificados, a demanda por maiores investimentos para a produção de energia aumentará. 
Tabela 2 - Participação relativa dos dez maiores setores na composição dos requerimentos de energia

\begin{tabular}{|c|c|c|c|c|c|c|c|c|}
\hline & \multirow{3}{*}{ MIP BR 2009 SETORES } & \multicolumn{7}{|c|}{ Requerimentos de energia } \\
\hline & & \multicolumn{2}{|c|}{ Direto } & \multicolumn{2}{|c|}{ Indireto } & \multicolumn{3}{|c|}{ Total } \\
\hline & & Valor & $\%$ & Valor & $\%$ & Valor & $\%$ & Ordem \\
\hline 3 & Energético & 0,100 & $21,7 \%$ & 0,362 & $78,3 \%$ & 0,463 & $100,0 \%$ & 1 \\
\hline 5 & Outros da indústria extrativa & 0,056 & $28,5 \%$ & 0,140 & $71,5 \%$ & 0,195 & $100,0 \%$ & 8 \\
\hline 14 & Produtos químicos & 0,082 & $27,5 \%$ & 0,216 & $72,5 \%$ & 0,298 & $100,0 \%$ & 2 \\
\hline 15 & Fabricação de resina e elastômeros & 0,080 & $33,9 \%$ & 0,155 & $66,1 \%$ & 0,235 & $100,0 \%$ & 3 \\
\hline 17 & Defensivos agrícolas & 0,059 & $30,6 \%$ & 0,133 & $69,4 \%$ & 0,192 & $100,0 \%$ & 6 \\
\hline 19 & Tintas, vernizes, esmaltes e lacas & 0,052 & $34,0 \%$ & 0,100 & $66,0 \%$ & 0,152 & $100,0 \%$ & 10 \\
\hline 22 & Cimento & 0,065 & $28,0 \%$ & 0,167 & $72,0 \%$ & 0,232 & $100,0 \%$ & 5 \\
\hline 23 & $\begin{array}{l}\text { Outros produtos de minerais não } \\
\text { metálicos }\end{array}$ & 0,054 & $29,3 \%$ & 0,130 & $70,7 \%$ & 0,184 & $100,0 \%$ & 9 \\
\hline 25 & Metalurgia de metais não ferrosos & 0,067 & $29,1 \%$ & 0,163 & $70,9 \%$ & 0,230 & $100,0 \%$ & 4 \\
\hline 40 & Transporte, armazenagem e correio & 0,057 & $24,7 \%$ & 0,173 & $75,3 \%$ & 0,230 & $100,0 \%$ & 7 \\
\hline & Média (53 setores) & 0,034 & $29,4 \%$ & 0,082 & $70,6 \%$ & 0,116 & $100,0 \%$ & \\
\hline
\end{tabular}

Fonte: elaboração dos autores.

Nota: A ordem de classificação de maior para menor contempla os 53 setores da economia.

A análise da composição dos requerimentos de energia, em termos de efeitos diretos e indiretos produzidos sobre o setor de energia, permite, de acordo com Perobelli, Mattos e Faria (2007), inferir que quanto menor a relação requerimentos diretos versus indiretos, maior o poder de multiplicação que a atividade de um dado setor exerce sobre o consumo de energia. Setores com alto peso na demanda de energia e que, ao mesmo tempo, apresentam uma baixa relação de requerimentos diretos versus indiretos tendem a produzir as mais fortes pressões de demanda sobre o setor de energia. No outro extremo, estariam setores com baixo peso na demanda de energia e com alta relação requerimentos diretos versus indiretos, que, neste caso, produziriam pequenas pressões sobre o setor de energia. Entre ambos os extremos, configuram-se setores com graus variados de importância na pressão que exercem.

A estrutura setorial dos requerimentos, apresentada na Tabela 2, mostra na economia brasileira que os requerimentos diretos, em média $(24,19 \%)$, são significativamente menores que os requerimentos indiretos $(75,81 \%)$. Essa baixa relação 
entre requerimentos diretos versus indiretos indica, em termos gerais, que os 53 setores da economia exercem significativa pressão sobre o setor energético.

Por sua vez, dentre os dez setores com maiores requerimentos totais do país, a baixa relação requerimentos diretos versus indiretos destaca principalmente os setores energético, transporte, armazenagem e correio, produtos químicos, Cimento, Outros da indústria extrativa, metalurgia de metais não ferrosos e Outros produtos de minerais não metálicos, como os que exercem forte pressão sobre a produção do setor energético brasileiro. Portanto, havendo um aumento na demanda final desses setores, aumentará muito mais os requerimentos de energia do que se houver um aumento de igual magnitude em outros setores da economia.

\subsection{Encadeamentos setoriais e coeficientes de dispersão do setor energético}

A análise do processo de interdependência setorial, além de permitir caracterizar as estruturas de produção e consumo, permite também determinar quais seriam os setores que teriam maior poder de encadeamento dentro da economia para promover o crescimento econômico, ou seja, os setores-chave. A identificação desses setores está associada à ideia de estabelecer prioridades na alocação de recursos e na estratégia de promoções industriais. Isso porque se espera que os recursos alocados em setores-chave, dependendo da política a ser implementada, estimulem um crescimento mais rápido da produção, do emprego e da interdependência econômica do que se fossem alocados em outros setores.

Nesse contexto, considerando estritamente a estrutura interna da economia, questiona-se: dentre os setores da economia brasileira, qual seria o poder de encadeamento que apresenta o setor energético.

A seguir, no Gráfico 3, são apresentados os índices de ligações setoriais para trás e para frente e, na Tabela 3, esses índices estão associados a seus coeficientes de dispersão para o ano de 2009. Em função do volume de informações gerado para os 53 setores da economia, a apresentação dos resultados destaca somente os resultados dos setores-chave na classificação restrita, ou seja, setores que apresentam simultaneamente índices de ligações maiores do que 1 para frente e para trás.

Os índices de Rasmussen e Hirschman para o ano de 2009 destacam oito setores-chave na economia brasileira, com ligações fortes tanto para frente como para trás (Gráfico 3). Certamente, para garantir o crescimento contínuo, torna-se necessário priorizar investimentos de expansão e de melhorias na infraestrutura desses setores, relevância que, segundo Myrdal (1972), Toyoshima e Ferreira 
(2002) e Torres e Puga (2006), são determinantes permanentes da renda per capita e da produtividade de um país, além de serem atrativos para captar investimentos internacionais. Os índices de ligações médios desses setores (Tabela 3) localizam-se entre os quatorze maiores da economia, com destaque para o setor energético que detém a maior média nacional, ou seja, trata-se de um setor que apresenta o maior encadeamento intersetorial da economia brasileira.

Gráfico 3 - Índices de ligações setoriais para frente e para trás da economia brasileira

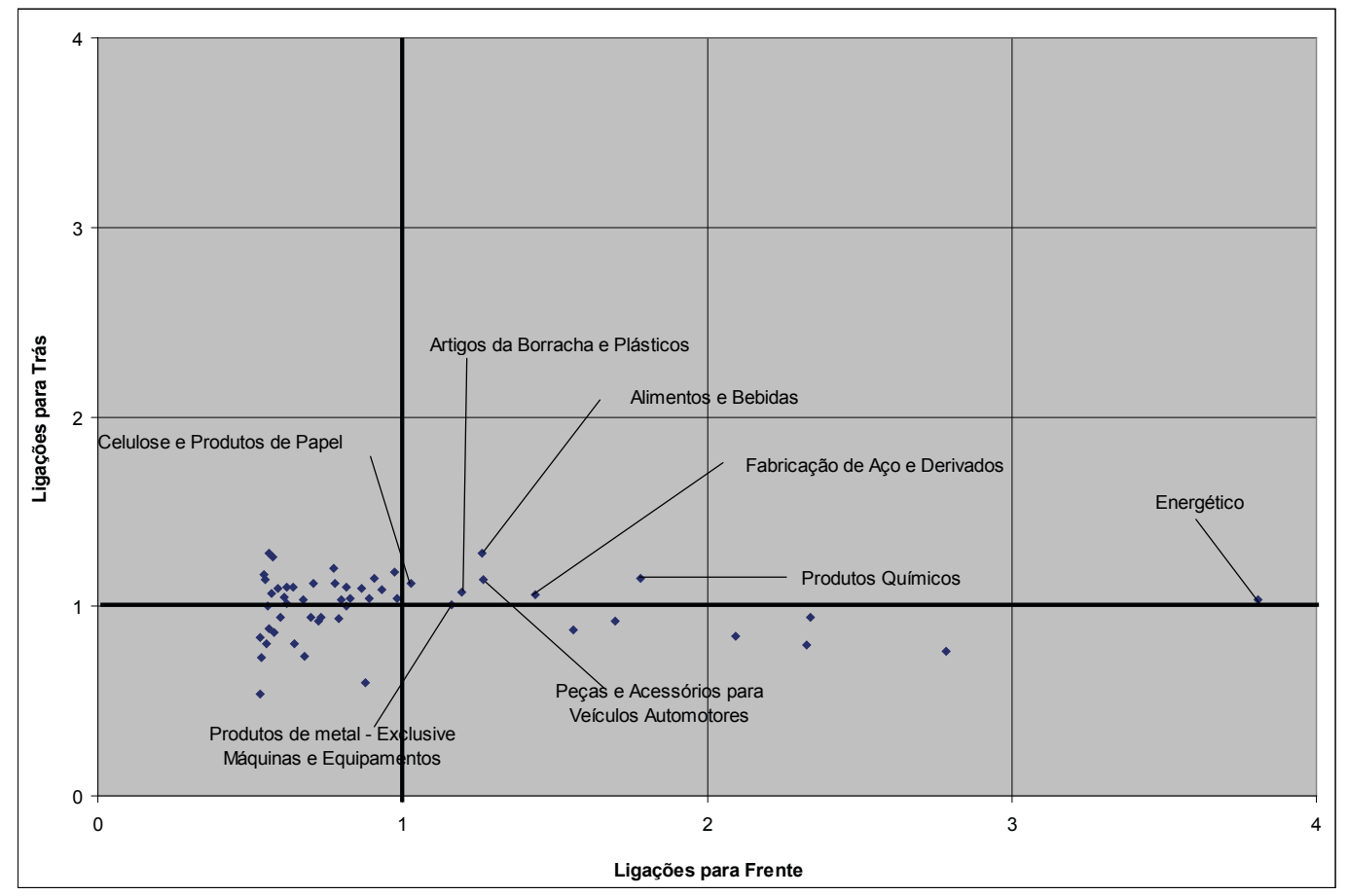

Fonte: elaboração dos autores.

Em particular, o setor energético apresenta, por um lado, um índice de ligação para trás de 1,0375, ocupando a vigésima sétima posição (ordem 27ª) e, por outro, um dos mais elevados coeficientes de dispersão $(5,4636)$, ocupando a quarta posição (ordem $4^{\mathrm{a}}$ ). Em conjunto, os índices demostram que se trata de um setor com encadeamentos setoriais de compra relevantes dentro da economia brasileira e seus estímulos, nos diversos setores da economia, pelo aumento da produção de energia são concentrados em poucos setores, em função do elevado coeficiente de dispersão que apresenta. Nesse sentido, a análise da estrutura de compras do setor energético 
apontava para essa evidência, já que o setor apresenta um nível elevado de autoabastecimento de insumos e também utiliza em sua produção uma parte significativa de insumos importados, o que concentra seus estímulos em poucos setores.

Tabela 3 - Índices de ligações de Rasmussen e Hirschman e coeficientes de dispersão de Bulmer para o ano de 2009

\begin{tabular}{|c|c|c|c|c|c|c|c|c|c|c|c|}
\hline & \multirow[t]{2}{*}{$\begin{array}{c}\text { MIP BR } 2009 \\
\text { SETORES }\end{array}$} & \multicolumn{4}{|c|}{ Ligação para trás } & \multicolumn{4}{|c|}{ Ligação para frente } & \multicolumn{2}{|c|}{$\begin{array}{l}\text { Média dos índi- } \\
\text { ces de ligação } \\
\text { de cada setor }\end{array}$} \\
\hline & & Índice & Ordem & Dispersão & Ordem & Índice & Ordem & Dispersão & Ordem & Valor & Ordem \\
\hline 3 & Energético & 1,0375 & 27 & 5,4636 & 4 & 3,8102 & 1 & 1,4554 & 52 & 2,4238 & 1 \\
\hline 6 & $\begin{array}{l}\text { Alimentos e } \\
\text { bebidas }\end{array}$ & 1,2812 & 1 & 3,8989 & 39 & 1,2626 & 11 & 3,9883 & 42 & 1,2719 & 8 \\
\hline 12 & $\begin{array}{l}\text { Celulose e } \\
\text { produtos de } \\
\text { papel }\end{array}$ & 1,1236 & 11 & 4,1017 & 30 & 1,0281 & 14 & 4,4411 & 38 & 1,0759 & 14 \\
\hline 14 & $\begin{array}{l}\text { Produtos quí- } \\
\text { micos }\end{array}$ & 1,1444 & 8 & 4,0361 & 32 & 1,7796 & 6 & 2,6068 & 48 & 1,4620 & 6 \\
\hline 21 & $\begin{array}{l}\text { Artigos de } \\
\text { borracha e } \\
\text { plástico }\end{array}$ & 1,0734 & 20 & 3,8587 & 40 & 1,1942 & 12 & 3,3769 & 44 & 1,1338 & 12 \\
\hline 24 & $\begin{array}{l}\text { Fabricação de } \\
\text { aço e derivados }\end{array}$ & 1,0632 & 22 & 4,0913 & 31 & 1,4374 & 9 & 3,0753 & 45 & 1,2503 & 9 \\
\hline 26 & $\begin{array}{l}\text { Produtos de } \\
\text { metal - exclusi- } \\
\text { ve máquinas e } \\
\text { equipamentos }\end{array}$ & 1,0061 & 31 & 4,1598 & 28 & 1,1618 & 13 & 3,5335 & 43 & 1,0840 & 13 \\
\hline 35 & $\begin{array}{l}\text { Peças e aces- } \\
\text { sórios para } \\
\text { veículos auto- } \\
\text { motores }\end{array}$ & 1,1416 & 9 & 4,3084 & 22 & 1,2652 & 10 & 4,0487 & 41 & 1,2034 & 11 \\
\hline
\end{tabular}

Fonte: elaborada pelos autores.

Nota: a ordem de classificação de maior para menor contempla os 53 setores da economia.

Analisando as ligações para frente que indicam o quanto um setor é demandado pelos outros setores, verifica-se, para o ano 2009, que o setor energético apresenta um índice maior do que 1, o que lhe confere a categoria de setor-chave para o crescimento da economia. Em particular, a importância relativa dos encadeamentos para frente posiciona o setor energético em primeiro lugar (ordem $1^{a}$ ) com um índice de 3,8102, acompanhado com um dos menores coeficientes de dispersão 
$(1,4554)$ do país, ocupando o quinquagésimo segundo lugar (ordem $52^{\mathrm{a}}$ ). Esses resultados conferem ao setor energético o status de ser o principal setor-chave para o crescimento nacional, por meio do fornecimento de insumos básicos, já que é fortemente demandado pelos outros setores da economia e seus estímulos sobre os diversos setores dão-se de maneira abrangente e uniforme em virtude dos baixos coeficientes de dispersão que apresenta.

\subsection{Os multiplicadores e o efeito-renda no setor energético}

Resta saber se esses estímulos promovem mais produção, renda, importações, impostos, salários, emprego. Assim, torna-se necessário avaliar os diversos multiplicadores econômicos do setor energético.

Embora calculados os multiplicadores para as diversas variáveis mencionadas, em função do número elevado de setores e da delimitação do objetivo desta pesquisa, apresenta-se na Tabela 4 somente os multiplicadores e a ordem em que 0 setor energético mostra-se acima da média nacional.

Considerando que os multiplicadores sinalizam a importância dos impactos diretos e indiretos de cada setor, para cada unidade produzida para a demanda final, verifica-se que o setor energético apresenta relevância na economia brasileira como gerador de produção, de emprego e de salários, uma vez que seus multiplicadores tipos I e II localizam-se acima da média nacional.

Em particular, esse setor apresenta um multiplicador de produção tipo I $(1,94)$ localizado na vigésima sétima posição (ordem 27aㅡ). Embora esse índice, dentre os 53 setores da economia, não represente ser um grande multiplicador, verifica-se que está acima da média, assinalando a importância do setor energético para a produção nacional. 
Tabela 4 - Os multiplicadores setoriais e o efeito-renda no setor energético. Valores e ordem de importância

\begin{tabular}{|c|c|c|c|c|c|c|}
\hline \multirow{2}{*}{ MULTIPLICADOR TIPO I } & \multicolumn{2}{|c|}{ Produção } & \multicolumn{2}{|c|}{ Emprego } & \multicolumn{2}{|c|}{ Salários } \\
\hline & valor & ordem & valor & ordem & valor & ordem \\
\hline 3 Energético & 1,943 & 27 & 7,733 & 9 & 2,665 & 12 \\
\hline 6 Alimentos e bebidas & 2,399 & 1 & 6,676 & 10 & 3,446 & 3 \\
\hline 12 Celulose e produtos de papel & 2,104 & 11 & 5,199 & 13 & 2,275 & 18 \\
\hline 14 Produtos químicos & 2,143 & 8 & 8,228 & 7 & 3,364 & 4 \\
\hline 21 Artigos de borracha e plástico & 2,010 & 20 & 2,379 & 26 & 1,916 & 26 \\
\hline 24 Fabricação de aço e derivados & 1,991 & 22 & 6,128 & 11 & 2,585 & 14 \\
\hline $\begin{array}{l}26 \text { Produtos de metal - exclusive máq. e } \\
\text { equip. }\end{array}$ & 1,884 & 31 & 1,657 & 36 & 1,735 & 34 \\
\hline $\begin{array}{l}35 \text { Peças e acessórios veículos automo- } \\
\text { tores }\end{array}$ & 2,138 & 9 & 3,080 & 22 & 2,107 & 21 \\
\hline Média nacional & 1,872 & & 4,043 & & 2,109 & \\
\hline \multicolumn{7}{|l|}{ MULTIPLICADOR TIPO II } \\
\hline 3 Energético & 3,629 & 25 & 30,373 & 6 & 6,657 & 9 \\
\hline 6 Alimentos e bebidas & 4,178 & 1 & 11,822 & 22 & 6,937 & 7 \\
\hline 12 Celulose e produtos de papel & 3,793 & 5 & 12,381 & 17 & 4,547 & 18 \\
\hline 14 Produtos químicos & 3,643 & 22 & 27,332 & 9 & 7,234 & 5 \\
\hline 21 Artigos de borracha e plástico & 3,549 & 37 & 6,612 & 27 & 3,712 & 31 \\
\hline 24 Fabricação de aço e derivados & 3,628 & 26 & 24,337 & 10 & 5,813 & 12 \\
\hline $\begin{array}{l}26 \text { Produtos de metal - exclusive máq. e } \\
\text { equip. }\end{array}$ & 3,627 & 27 & 4,493 & 33 & 3,531 & 33 \\
\hline $\begin{array}{l}35 \text { Peças e acessórios veículos automo- } \\
\text { tores }\end{array}$ & 3,767 & 8 & 9,211 & 23 & 3,889 & 27 \\
\hline Média nacional & 3,616 & & 11,870 & & 4,469 & \\
\hline \multicolumn{7}{|l|}{ EFEITO-RENDA } \\
\hline 3 Energético & 1,687 & 33 & 22,641 & 4 & 3,992 & 4 \\
\hline 6 Alimentos e bebidas & 1,779 & 25 & 5,145 & 25 & 3,491 & 7 \\
\hline 12 Celulose e produtos de papel & 1,689 & 32 & 7,182 & 21 & 2,272 & 19 \\
\hline 14 Produtos químicos & 1,500 & 49 & 19,104 & 8 & 3,871 & 5 \\
\hline 21 Artigos de borracha e plástico & 1,539 & 45 & 4,233 & 27 & 1,796 & 34 \\
\hline 24 Fabricação de aço e derivados & 1,637 & 39 & 18,209 & 10 & 3,228 & 10 \\
\hline $\begin{array}{l}26 \text { Produtos de metal - exclusive máq. e } \\
\text { equip. }\end{array}$ & 1,743 & 29 & 2,836 & 33 & 1,796 & 35 \\
\hline $\begin{array}{l}35 \text { Peças e acessórios veículos automo- } \\
\text { tores }\end{array}$ & 1,629 & 40 & 6,131 & 22 & 1,782 & 36 \\
\hline Média nacional & 1,743 & & 7,827 & & 2,359 & \\
\hline
\end{tabular}

Fonte: elaboração dos autores.

Nota: a ordem de classificação de maior para menor contempla os 53 setores da economia. 
Desse modo, o setor energético configura-se como um dos nove setores mais importantes na geração de emprego, com um índice de 7,73, valor superior à média nacional (4,04). Assim, se fosse criada uma unidade de emprego no setor energético, na economia brasileira, seriam gerados 7,73 novos postos de trabalho, ou seja, um indivíduo trabalhando no próprio setor energético e 6,73 novos indivíduos trabalhando nos demais setores da economia.

A importância do setor energético também se revela pelo lado dos salários, por apresentar um multiplicador salarial $(2,66)$ acima da média $(2,11)$ e localizar-se no décimo segundo lugar (ordem $12^{\mathrm{a}}$ ) da economia brasileira. Igualmente, pode-se afirmar que os novos empregos por conta desse setor são acrescidos também de 2,66 novos salários na economia para cada unidade monetária produzida para a demanda final.

Por sua vez, os multiplicadores tipo II, que captam o efeito induzido do consumo das famílias, corroboram a importância relativa do setor energético como gerador de produção, emprego e salários. Em particular, verifica-se com a endogenização do consumo das famílias que o multiplicador de produção aumentou 1,87, o do emprego, 3,93, e o de salários, 2,50 vezes. Em virtude desses fatos, na ordem de importância, o setor avançou três posições em emprego (de $9^{\mathrm{a}}$ para $6^{\mathrm{a}}$ ordem) e salários (de $12^{\mathrm{a}}$ para $9^{\mathrm{a}}$ ordem) e duas posições em produção (de $27^{\mathrm{a}}$ para $25^{\mathrm{a}}$ ). Como resultado, o setor energético torna-se tão relevante que, para cada unidade produzida para a demanda final, gera 3,63 unidades na produção, 30,37 novos empregos e 6,66 novos salários.

Entretanto, é necessário, para entender melhor a inserção estratégica do setor na economia, avaliar o efeito-renda obtido pela diferença dos multiplicadores tipos I e II. Os valores e a ordem do efeito-renda deixam em evidência que as oportunidades relacionadas à maior geração de empregos e salários por meio do aumento da produção para a demanda final parecem substancialmente maiores para o setor energético do que para outros setores da economia. Isso porque o efeito-renda esse setor localiza-se entre os quatro mais importantes da economia, ou seja, trata-se de um setor em que a renda das famílias induz significativamente o emprego e os salários.

\section{Impactos do aumento da demanda final do setor energético na produção, no emprego e nos salários}

Considerando a relevância identificada do setor energético sobre produção, emprego e salários, seguem-se algumas considerações sobre as simulações que foram elaboradas nesta pesquisa. Uma vez que os impactos da demanda final do setor energético sobre a economia brasileira foram calculados utilizando-se a MIP 
de 2009, neste exercício, considera-se que as relações tecnológicas de insumo-produto permaneceram estáveis entre 2009 e 2015. Embora saibamos que as relações tecnológicas mudam no tempo, acreditamos que, em função da estabilidade macroeconômica e tecnológica, as mudanças estruturais da economia tendem a ser relativamente lentas.

Para avaliar os impactos do setor, foram utilizados como referência os dados do Balanço Energético Nacional. Segundo as projeções do IEO (2010), o consumo de energia crescerá $2,4 \%$ ao ano, fazendo com que a demanda final de energia aumente em $15,62 \%$ no período, passando de 220.711 milhões de tep em 2009 para 255.180 milhões de tep em 2015 (BERS, 2010).

Para efetuar a simulação dos impactos do crescimento, a variação percentual do consumo de energia em tep foi transformada em valor monetário, utilizando-se a estrutura da demanda final da MIP. Com esse procedimento, apurou-se um aumento do valor da demanda final do setor energético da ordem $\mathrm{R} \$ 20.199$ milhões para 2015. Na simulação, esses valores foram acrescidos ao setor energético. Portanto, os impactos devem ser interpretados como sendo decorrentes da maior pressão dos diversos setores de produção e de consumo por maior volume de energia. Assim, os resultados mostram o crescimento potencial da economia de 2009 a 2015 , por conta exclusivamente do aumento de $15,62 \%$ na demanda final do consumo de energia.

$\mathrm{Na}$ Tabela 5, os resultados globais da simulação sobre a produção para o ano de 2015 indicam que, caso se concretize o aumento do consumo de energia em $\mathrm{R} \$ 20.199$ milhões, a economia brasileira terá um acréscimo em seu valor da produção na ordem de $\mathrm{R} \$ 73.306$ milhões, ou seja, ocorrerá um efeito multiplicador do setor energético sobre a produção de $3,629(\mathrm{R} \$ 73.306 \div \mathrm{R} \$ 20.199=3,629)$, conforme também consta na Tabela 4.

Tabela 5 - Impacto total da demanda final do setor energético sobre a produção, emprego e salários da economia brasileira para o ano de 2015, com base em dados de 2009

\begin{tabular}{l|r|r|r|r|r}
\hline \multicolumn{1}{|c|}{ Ano } & $\begin{array}{c}\text { Consumo de } \\
\text { energia final em } \\
\text { milhões de tep }\end{array}$ & $\begin{array}{c}\text { Demanda final } \\
\text { do setor energé- } \\
\text { tico em milhões } \\
\text { de reais }\end{array}$ & $\begin{array}{c}\text { Valor da } \\
\text { produção } \\
\text { em milhões } \\
\text { de reais }\end{array}$ & Emprego & $\begin{array}{l}\text { Salários em } \\
\text { milhões de } \\
\text { reais }\end{array}$ \\
\hline 2009 & 220.711 & 129.337 & 5.480 .741 & 96.647 .139 & 206.104 \\
2015 & 255.180 & 149.536 & 5.554 .047 & 97.529 .367 & 215.876 \\
Variação percentual 2009-2015 & $15,62 \%$ & $15,62 \%$ & $1,34 \%$ & $0,91 \%$ & $4,74 \%$ \\
Impacto líquido 2009-2015 & 34.469 & 20.199 & 73.306 & 882.228 & 9.772 \\
\hline
\end{tabular}

Fonte: elaboração dos autores. 
A distribuição desses efeitos, conforme a Tabela 6, indica que o setor mais estimulado e/ou beneficiado pelo consumo de energia é o próprio setor energético com $44,62 \%$, seguido pelos serviços com $33,48 \%$, indústria com $17,66 \%$, e agropecuária com $4,24 \%$. Com base nessa distribuição, pode-se afirmar que o setor energético promove significativamente o crescimento da produção, já que mais da metade dos impactos $(55,38 \%)$ ocorrerão fora do setor e, dentre eles, os setores serviços e indústria são os mais estimulados. Portanto, pelo lado da produção, os volumes de investimentos disponíveis para aumentar a oferta de energia deverão levar em consideração o peso dos setores na distribuição dos impactos identificados.

No caso da mão de obra, os resultados mostram para 2015 a geração de 882.228 novos empregos, e quanto à distribuição dos benefícios, eles concentram-se majoritariamente no setor serviços com 59,53\%, seguido da agropecuária com $21,81 \%$ e da indústria com $13,33 \%$, cabendo a menor participação ao setor energético $(5,33 \%)$. Assim, se consideramos que o multiplicador de emprego do setor é 30,373 (882.228 novos empregos $\div 29.046$ empregos diretos ou iniciais $=30,373)$ e simultaneamente apresenta uma pequena participação na distribuição dos efeitos, torna-se evidente que o setor energético estimula de forma significativa e abrangente a geração de emprego nos mais diversos setores da economia brasileira.

Por sua vez, os novos salários gerados pelo aumento do consumo de energia alcançam o montante de $\mathrm{R} \$ 9.772$ milhões. A distribuição desses efeitos indica que os maiores benefícios concentram-se no setor serviços $(54,54 \%)$, seguido de longe pelos setores energético $(24,32 \%)$, indústria $(16,09 \%)$ e agropecuária $(5,05 \%)$. Concomitantemente, quando dividimos o montante dos novos salários com os novos empregos, verifica-se maior concentração de benefícios salariais por setores: enquanto o salário médio do país alcança a ordem de $\mathrm{R} \$ 11.076$, no setor energético o salário alcança o valor de $R \$ 50.536$, na indústria $R \$ 13.366$, nos serviços $R \$$ 10.148 , e na agropecuária somente $\mathrm{R} \$ 2.563$. Esses fatos, em particular o do setor energético, certamente, estão associados a padrões salarias diferenciados (por exemplo, na extração de petróleo por conta da especialização e riscos) bem como a concentração industrial da produção de energia. 
Tabela 6 - Impacto total de um aumento de 15,62\% da demanda final do setor energético sobre a produção,emprego e salários dos setores agregados da economia brasileira para o ano de 2015, com base em 2009

\begin{tabular}{l|r|r|r|r|r|r}
\hline \multirow{2}{*}{$\begin{array}{c}\text { Setores } \\
\text { agregados }\end{array}$} & \multicolumn{2}{|c|}{ Produção } & \multicolumn{2}{c|}{ Emprego } & \multicolumn{2}{c}{ Salários } \\
\cline { 2 - 7 } & $\begin{array}{c}\text { Valor em } \\
\text { milhões }\end{array}$ & $\begin{array}{c}\text { Distribuição } \\
\text { dos efeitos (\%) }\end{array}$ & Números & $\begin{array}{c}\text { Distribuição } \\
\text { dos efeitos (\%) }\end{array}$ & $\begin{array}{c}\text { Valor em } \\
\text { milhões }\end{array}$ & $\begin{array}{c}\text { Distribuição } \\
\text { dos efeitos (\%) }\end{array}$ \\
\hline Agropecuária & 3.109 & 4,24 & 192.397 & 21,81 & 493 & 5,05 \\
Energético & 32.708 & 44,62 & 47.034 & 5,33 & 2.377 & 24,32 \\
Indústria & 12946 & 17,66 & 117640 & 13,33 & 1572 & 16,09 \\
Serviços & 24.543 & 33,48 & 525.157 & 59,53 & 5.329 & 54,54 \\
\hline Total & 73.306 & 100,00 & 882.228 & 100,00 & 9.772 & 100,00 \\
\hline
\end{tabular}

Fonte: elaboração dos autores.

Nesse contexto, uma análise setorial mais desagregada torna-se necessária para identificar os principais setores mais afetados pelo aumento do consumo de energia. Os impactos diretos, indiretos, induzidos e totais sobre a produção, o emprego e os salários em cada um dos setores encontram-se nos Anexos A, B e C, respectivamente.

O Quadro 1 mostra os setores que sofreram impactos acima da média nacional. Os impactos diretos representam o choque de produção inicial devido ao aumento do consumo de energia; os impactos indiretos refletem os fluxos de compras e vendas dos setores por conta do maior consumo de energia; e os impactos induzidos representam os efeitos do aumento do consumo de energia sobre a renda da economia que, por sua vez, afetam o consumo final das famílias.

Em geral, se consideramos que os impactos diretos mostram os setores que estão mais diretamente ligados com o setor energético, verifica-se, no Quadro 1, tanto na produção, no emprego e nos salários que, além do próprio setor, que a grande maioria dos diversos segmentos que conformam o setor terciário do país pressiona significativamente a produção de energia. Assim, pode-se afirmar que o setor energético está fortemente interligado à economia brasileira por meio dos serviços, tais como: os serviços prestados às empresas (46), o transporte, a armazenagem e o correio (40), o comércio (39), os serviços de informação (41), os serviços imobiliários e de aluguel (43), a intermediação financeira e os seguros (42) e os serviços prestados às famílias e associativas (49). 
Quadro 1 - Setores mais impactados pelo setor energético com relação à produção, emprego e salários no Brasil - organizados de maior para menor

\begin{tabular}{|c|c|c|}
\hline Impacto indireto & Impacto induzido & Impacto total \\
\hline \multicolumn{3}{|c|}{ Produção } \\
\hline $\begin{array}{l}3 \text { Energético } \\
46 \text { Serviços prestados } \\
\text { às empresas } \\
40 \text { Transporte, } \\
\text { armazenagem e correio } \\
1 \text { Agricultura, silvicultura, } \\
\text { exploração florestal } \\
41 \text { Serviços de } \\
\text { informação } \\
43 \text { Serviços imobiliários } \\
\text { e aluguel } \\
42 \text { Intermediação } \\
\text { financeira e seguros }\end{array}$ & $\begin{array}{l}39 \text { Comércio } \\
6 \text { Alimentos e bebidas } \\
3 \text { Energético } \\
43 \text { Serviços imobiliários e aluguel } \\
42 \text { Intermediação financeira e } \\
\text { seguros } \\
40 \text { Transporte, armazenagem e } \\
\text { correio } \\
41 \text { Serviços de informação } \\
1 \text { Agricultura, silvicultura, exploração } \\
\text { florestal } \\
46 \text { Serviços prestados às } \\
\text { empresas } \\
45 \text { Serviços de alojamento e } \\
\text { alimentação } \\
48 \text { Saúde mercantil } \\
2 \text { Pecuária e pesca } \\
49 \text { Serviços prestados às famílias } \\
\text { e associativas }\end{array}$ & $\begin{array}{l}3 \text { Energético } \\
39 \text { Comércio } \\
6 \text { Alimentos e bebidas } \\
40 \text { Transporte, } \\
\text { armazenagem e correio } \\
43 \text { Serviços imobiliários e } \\
\text { aluguel } \\
42 \text { Intermediação } \\
\text { financeira e seguros } \\
46 \text { Serviços prestados às } \\
\text { empresas } \\
41 \text { Serviços de informação } \\
1 \text { Agricultura, silvicultura, } \\
\text { exploração florestal }\end{array}$ \\
\hline \multicolumn{3}{|c|}{ Emprego } \\
\hline $\begin{array}{l}1 \text { Agricultura, silvicultura, } \\
\text { exploração florestal } \\
46 \text { Serviços prestados } \\
\text { às empresas } \\
39 \text { Comércio } \\
40 \text { Transporte, } \\
\text { armazenagem e correio } \\
3 \text { Energético } \\
49 \text { Serviços prestados } \\
\text { às famílias e } \\
\text { associativas } \\
41 \text { Serviços de } \\
\text { informação } \\
38 \text { Construção } \\
26 \text { Produtos de metal } \\
\text { - exclusive máquinas e } \\
\text { equipamentos }\end{array}$ & $\begin{array}{l}39 \text { Comércio } \\
1 \text { Agricultura, silvicultura, exploração } \\
\text { florestal } \\
50 \text { Serviços domésticos } \\
2 \text { Pecuária e pesca } \\
45 \text { Serviços de alojamento e } \\
\text { alimentação } \\
49 \text { Serviços prestados às famílias } \\
\text { e associativas } \\
40 \text { Transporte, armazenagem e } \\
\text { correio } \\
46 \text { Serviços prestados às } \\
\text { empresas } \\
6 \text { Alimentos e bebidas } \\
9 \text { Artigos do vestuário e acessórios } \\
44 \text { Serviços de manutenção e } \\
\text { reparação } \\
48 \text { Saúde mercantil } \\
47 \text { Educação mercantil } \\
41 \text { Serviços de informação }\end{array}$ & $\begin{array}{l}1 \text { Agricultura, silvicultura, } \\
\text { exploração florestal } \\
39 \text { Comércio } \\
50 \text { Serviços domésticos } \\
46 \text { Serviços prestados às } \\
\text { empresas } \\
40 \text { Transporte, } \\
\text { armazenagem e correio } \\
3 \text { Energético } \\
2 \text { Pecuária e pesca } \\
45 \text { Serviços de alojamento } \\
\text { e alimentação } \\
49 \text { Serviços prestados às } \\
\text { famílias e associativas } \\
6 \text { Alimentos e bebidas } \\
44 \text { Serviços de } \\
\text { manutenção e reparação } \\
9 \text { Artigos do vestuário e } \\
\text { acessórios } \\
41 \text { Serviços de informação } \\
48 \text { Saúde mercantil } \\
47 \text { Educação mercantil }\end{array}$ \\
\hline
\end{tabular}




\begin{tabular}{|c|c|c|}
\hline \multicolumn{3}{|c|}{ Salários } \\
\hline $\begin{array}{l}3 \text { Energético } \\
46 \text { Serviços prestados } \\
\text { às empresas } \\
40 \text { Transporte, } \\
\text { armazenagem e correio } \\
39 \text { Comércio } \\
1 \text { Agricultura, silvicultura, } \\
\text { exploração florestal } \\
\mathbf{4 2} \text { Intermediação } \\
\text { financeira e seguros } \\
\mathbf{4 1} \text { Serviços de } \\
\text { informação } \\
30 \text { Máquinas, aparelhos e } \\
\text { materiais elétricos } \\
26 \text { Produtos de metal } \\
\text { - exclusive máquinas e } \\
\text { equipamentos }\end{array}$ & $\begin{array}{l}39 \text { Comércio } \\
42 \text { Intermediação financeira e } \\
\text { seguros } \\
40 \text { Transporte, armazenagem e } \\
\text { correio } \\
51 \text { Educação pública } \\
46 \text { Serviços prestados às } \\
\text { empresas } \\
6 \text { Alimentos e bebidas } \\
47 \text { Educação mercantil } \\
48 \text { Saúde mercantil } \\
50 \text { Serviços domésticos } \\
49 \text { Serviços prestados às famílias } \\
\text { e associativas } \\
3 \text { Energético } \\
1 \text { Agricultura, silvicultura, exploração } \\
\text { florestal } \\
2 \text { Pecuária e pesca }\end{array}$ & $\begin{array}{l}3 \text { Energético } \\
39 \text { Comércio } \\
46 \text { Serviços prestados às } \\
\text { empresas } \\
40 \text { Transporte, } \\
\text { armazenagem e correio } \\
42 \text { Intermediação } \\
\text { financeira e seguros } \\
50 \text { Serviços domésticos } \\
41 \text { Serviços de informação } \\
1 \text { Agricultura, silvicultura, } \\
\text { exploração florestal } \\
6 \text { Alimentos e bebidas } \\
47 \text { Educação mercantil } \\
49 \text { Serviços prestados às } \\
\text { famílias e associativas } \\
48 \text { Saúde mercantil } \\
45 \text { Serviços de alojamento e } \\
\text { alimentação }\end{array}$ \\
\hline
\end{tabular}

Fonte: elaboração dos autores.

Nota: o quadro enumera os setores do maior ao menor, contemplando os 53 setores da economia, embora o número de cada setor seja discrepante.

Além disso, o Quadro 1 destaca também os setores agricultura, silvicultura, exploração florestal (1) entre os mais atingidos pelo aumento do consumo de energia. Certamente, isso se deve ao fato de $23,58 \%$ do consumo de energia nacional ter sua origem, segundo o BEN (2009), nos produtos da cana, na casca de arroz e na lenha, ou seja, nas atividades da agricultura e exploração florestal. Os impactos diretos mostram também os setores construção (38), máquinas, aparelhos e materiais elétricos (30) e produtos de metal - exclusive máquinas e equipamentos (26) como aqueles que estão ligados ao setor energético.

Com relação aos impactos induzidos, pode-se afirmar que eles são mais dispersos porque decorrem do aumento da circulação de renda na economia. Assim, esses impactos podem atingir fortemente setores que não apresentam nenhuma aparente relação tecnológica com o setor energético, mas apresenta com o consumo das famílias. Contudo, percebe-se novamente a predominância de uma série de segmentos do setor terciário. Note-se também que o efeito-renda ou induzido, além de assinalar os setores agropecuária (setores 1 e 2) e energético (3) como os mais afetados, destaca sobretudo o aumento do consumo das famílias nos setores alimentos e bebidas (6) e artigos do vestuário e acessórios (9). 
Finalmente, os impactos totais compostos pela soma dos impactos indiretos e induzidos mostram, no Quadro 1, os setores mais estimulados pelo aumento de consumo de energia, e eles, por sua vez, representam, com base na estrutura setorial da MIP, 49,75\% do VBP, 50,22\% dos empregos e 71,86\% dos salários. Observa-se também que, dentre eles, a maioria dos setores da indústria não estão presentes, a razão para isso é o fato de esses setores não apresentarem relações tecnológicas significativas com o setor energético, mas, sim, com a grande maioria dos setores de serviços que distribuem o insumo energia no sistema econômico. Portanto, os dados sugerem que a pressão por maiores níveis de energia se canalizarão pelo setor terciário da economia brasileira.

\section{Considerações finais}

Considerando as perspectivas de aumento do consumo de energia nos próximos anos, este estudo teve como objetivo avaliar intersetorialmente a importância relativa do setor energético para o crescimento da economia brasileira por meio do modelo insumo-produto de 2009. Para isso, analisaram-se as compras e vendas do setor energético, os requerimentos setoriais de energia, os índices de encadeamento, os multiplicadores setoriais, bem como se simulou, com base nas projeções do aumento de consumo de energia na demanda final, impactos sobre a produção, emprego e salários.

Verificou-se que o setor energético apresenta elevado autoabastecimento de insumos, detém uma participação relativamente pequena no VBP e no PIB, e constitui-se um importante fornecedor de insumo para as indústrias e de produtos para as famílias e para o mercado exportador.

$\mathrm{Na}$ estrutura dos requerimentos setoriais, a baixa relação média de requerimentos diretos versus indiretos que apresenta a economia brasileira permitiu verificar que todos os setores produtivos exercem significativa pressão sobre o setor energético. Principalmente, destacam-se os setores energético, transporte, armazenagem e correio, produtos químicos, cimento, outros da indústria extrativa, metalurgia de metais não ferrosos e outros produtos de minerais não metálicos como os que exercem forte pressão sobre o setor energético nacional. Isto é, havendo um aumento na demanda final desses setores, aumentará muito mais os requerimentos de energia do que se houver um aumento de igual magnitude em outros setores da economia.

Com base nos encadeamentos setoriais e nos índices de dispersão, verificou-se que o setor energético é o principal setor-chave do país que promove, por um lado, 
com suas ligações para trás o crescimento de forma concentrada em alguns setores da economia e, por outro, com suas ligações para frente, como fornecedor de insumos básicos, estimula de forma abrangente e uniforme o crescimento econômico nos diversos setores da economia brasileira.

Nesse sentido, os multiplicadores setoriais e o efeito-renda permitiram verificar que o setor energético apresenta relevância nacional, estimulando o crescimento na produção, no emprego e nos salários. Em particular, verificou-se com a endogenização do consumo das famílias que o setor gera, por cada unidade produzida para a demanda final, 3,63 unidades na produção, 30,37 novos empregos e 6,66 novos salários.

As simulações do impacto de um aumento na demanda final do setor energético sobre a produção, emprego e salários mostraram, em geral, que, além do próprio setor, a grande maioria dos diversos segmentos que conformam o setor terciário do país é afetada pelo consumo de energia. Verificou-se também que a maioria dos setores da indústria não consta entre os mais afetados pelos impactos simulados, isso porque eles não apresentam relações tecnológicas significativas com o setor energético, mas sim com os componentes do setor terciário, que distribuem ou utilizam os insumos energéticos para atender as necessidades da indústria. Portanto, podemos concluir que os setores serviços, para os próximos anos, constituir-se-ão nos principais canais de transmissão dos impactos de um maior consumo de energia na economia brasileira.

Em síntese, trata-se de um setor estratégico que estimula o crescimento econômico de forma abrangente e, pelo fato de ser requerido permanentemente no sistema econômico, precisa de um fluxo contínuo de investimentos. 


\title{
Inter sectoral affairs of the energy sector in the Brazilian economy: an input-output approach
}

\begin{abstract}
The article evaluates the sectoral Inter relations of the Energy sector in the Brazilian economy using the input-output matrix estimated for 2009. It was found that the Energy sector constitutes the main key sector of the economy, stimulates comprehensively economic growth and its stimuli stand out in the generation of production, jobs and wages. The simulations on the Energy sector showed that the services sectors are the main channels of transmission of the impacts of higher energy consumption in the Brazilian economy. It is, therefore, a strategic sector for economic growth that needs a continuous flow of investments to increase production.
\end{abstract}

Keywords: Energy sector. Economic growth. Energy requirements. Input-output.

JEL Classification: Q41, D57, C67, R10

\section{Las relaciones inter-sectoriales del sector de la energía en la economía brasileña: un enfoque de insumo-producto}

\section{Resumen}

El artículo evalúa las relaciones inter sectoriales del sector de la energía en la economía brasileña utilizando la matriz de insumo-producto estimada para 2009. Se encontró que el sector de la energía es el principal sector clave de la economía, estimula el crecimiento económico integral y su estímulos se destacan en la generación de producción, el empleo y los salarios. Las simulaciones en el sector Energía mostraron que los sectores de servicios son los principales canales de transmisión de los impactos de un mayor consumo de energía en la economía brasileña. Es, por lo tanto, un sector estratégico para el crecimiento económico que necesita un flujo continuo de inversiones para aumentar la producción.

Palabras clave: El sector energético. El crecimiento económico. Los requisitos de energía. Insumo-producto.

\section{Referências}

BERS. BALANÇO ENERGÉTICO DO RIO GRANDE DO SUL 2010: ano base 2009. Gilberto José Capeletto e Gustavo Humberto Zanchi de Moura. POA, Grupo CEEE/Secretaria de infraestrutura e logística do Rio Grande do Sul, 2010. 240 p.

BRASIL. Ministério de Energia e Minas. Portal 2013. Disponível em: <http://www.brasil.gov.br/ sobre/economia/energia/matriz-energetica>. Acesso em: 22 maio 2013. 
BULMER, V. Input-output analysis in developing countries. New York: John Wiley, 1982.

CARNEIRO, A. C. G.; FIGUEIREDO, N. R. M.; ARAÚJO JÚNIOR, I. T. Utilização da matriz insumo-produto híbrida para avaliar os efeitos da substituição de óleo combustível por gás natural na matriz energética brasileira. Foz de Iguaçu: Anpec. 2009. Disponível em: <http//www. anpec.org.br/encontro2009>. Acesso em: 6. jun. 2011.

EPE. Empresa de Pesquisa Energética (Brasil). Balanço Energético Nacional 2012: ano base 2011. Rio de Janeiro: EPE, 2012. p. 180. Disponível em: <https://ben.epe.gov.br/BENRelatorioFinal2012.aspx.>. Acesso em: 6 jun. 2012.

FINAMORE, E. B.; MONTOYA, M. A. Avaliação de impactos econômicos no Rio Grande do Sul: uma abordagem de insumo-produto. Passo Fundo: UPF Editora, 2013. 134 p.

FIRME, C. V. A.; PEROBELLI, F. S. O setor energético brasileiro: uma análise via indicadores de insumo-produto e o modelo híbrido para os anos de 1997 e 2002. Planejamento e Políticas Públicas, Rio de Janeiro, n. 39, jul./dez. 2012.

FOCHEZATTO, A.; GRANDO, M. Z. Efeitos da estiagem de 2008 na economia do Rio Grande do Sul: uma abordagem multissetorial. Ensaios FEE, Porto Alegre, v. 32, n. 1, p. 137-160, jun. 2011.

GUILHOTO, J. J. M. Análise de insumo-produto: teoria e fundamentos. São Paulo: Apostilha. USP. n. 32.566, 5 Aug. 2011. Disponível em: <http://mpra.ub.uni-muenchen.de/32566/>. Acesso em: 8 abr. 2012 .

GUILHOTO, J. J. M.; SESSO FILHO, U. A. Estimação da matriz insumo-produto a partir de dados preliminares dascContas nacionais. Economía Aplicada, Ribeirão Preto, v. 9, n. 2, p. 277-299. abr./jun. 2005.

GUILHOTO, J. J. M.; SESSO FILHO, U. A. Estimação da matriz insumo-produto utilizando dados preliminares das contas nacionais: aplicação e análise de indicadores econômicos para 0 Brasil em 2005. Economia \& Tecnologia, Paraná, a. 6, v. 23, out 2010.

HILGEMBERG, E. M.; GUILHOTO, J. J. M. Uso de combustíveis e emissões de $\mathrm{CO}_{2}$ no Brasil: um modelo inter-regional de insumo-produto. Nova Economia, Minas Gerais, v. 16, n. 1, p. 49-99, abr. 2006.

HIRSCHMAN, A. The strategy of economic development. New Haven: Yale University Press, 1958.

IEO - INTERNATIONAL ENERGY OUTLOOK 2010. Disponível em: <http//www.eia.doe.gov>. Acesso em: 11 jun. 2011.

LEONTIEF, W. A economia do insumo-produto. São Paulo: Fundo de cultura, 1983. 227 p. 1951. The structure of the americam economy. 2. ed. amp. New York: Oxford University Press,

MATTOS, R. S. Interações setoriais sobre a demanda de energia elétrica em Pernambuco: uma análise inter-regional de insumo-produto. Juiz de Fora: ENABER, 2010. Disponível em: <http// www.estudosregionais.org.br>. Acesso em: 8 jun. 2011.

MONTOYA, M. A. et al. Evolução do uso de energia na estrutura de produção e consumo do Rio Grande do Sul: uma abordagem insumo-produto. Teoria e Evidência Econômica, Passo Fundo, a. 17, n. 37, p. 193-219, jul./dez. 2011. 
MONTOYA, M. A. et al. Consumo de energia, emissões de $\mathrm{CO}_{2}$ e a geração de emprego e renda no agronegócio brasileiro: uma análise insumo-produto. NEREUS. São Paulo: TD Nereus, jul. 2013. Disponível em: <http://www.usp.br/nereus/?td=nova-serie>. Acesso em: 8 abr. 2013.

MONTOYA, M. A.; LOPES, R. L.; GUILHOTO, J. J. M. Desagregação setorial do balanço energético nacional a partir dos dados da matriz insumo-produto: uma avaliação metodológica. $N E$ REUS, São Paulo: TD Nereus, maio 2013. Disponível em: <http://www.usp.br/nereus/?td=nova-serie>. Acesso em: 8 abr. 2013.

MYRDAL, G. Teoria econômica e regiões subdesenvolvidas. 3. ed. Rio de Janeiro: Saga, 1972.

PEROBELLI, F. S.; MATTOS, R. S.; FARIA, W. R. A interdependência energética entre o estado de Minas Gerais e o restante do Brasil: uma análise inter-regional de insumo-produto. Economia Aplicada, Ribeirão Preto, v. 11, n. 1, p. 113-130, jan./mar. 2007.

RASMUSSEN, P. N. Studies in inter-sectorial relations. Amsterdam: North-Holland, 1956. 217 p.

TORRES FILHO, E. T.; PUGA, F. P. Os rumos dos investimentos em infraestrutura. Visão do desenvolvimento, Rio de Janeiro, n. 20, p. 1-8, nov. 2006.

TOYOSHIMA, S.; FERREIRA, M. J. Encadeamento do setor de transportes na economia brasileira. Planejamento e políticas públicas, n. 25, dez. 2002. 


\section{Anexo A}

Tabela 1 - Impacto direto, indireto e induzido de um aumento de $15,62 \%$ da demanda final do setor energético sobre a produção dos setores da economia brasileira para o ano de 2015 , com base em 2009

\begin{tabular}{|c|c|c|c|c|c|c|}
\hline \multirow{3}{*}{ Setores } & \multicolumn{6}{|c|}{ Produção } \\
\hline & \multicolumn{4}{|c|}{ Impactos em milhões de $\mathrm{R} \$$} & \multicolumn{2}{|c|}{$\begin{array}{l}\text { Distribuição dos } \\
\text { efeitos totais }\end{array}$} \\
\hline & Direto & Indireto & Induzido & Total & Percentual & Ordem \\
\hline $\begin{array}{l}1 \text { Agricultura, silvicultura, explora- } \\
\text { ção florestal }\end{array}$ & 0 & 833 & 1375 & 2.208 & 3,01 & 9 \\
\hline 2 Pecuária e pesca & 0 & 54 & 847 & 901 & 1,23 & 13 \\
\hline 3 Energético & 20.199 & 9.343 & 3.166 & 32.708 & 44,62 & 1 \\
\hline 4 Minério de ferro & 0 & 15 & 19 & 33 & 0,05 & 50 \\
\hline 5 Outros da indústria extrativa & 0 & 53 & 64 & 117 & 0,16 & 43 \\
\hline 6 Alimentos e bebidas & 0 & 194 & 3357 & 3.551 & 4,84 & 3 \\
\hline 7 Produtos do fumo & 0 & 0 & 98 & 98 & 0,13 & 44 \\
\hline 8 Têxteis & 0 & 22 & 391 & 413 & 0,56 & 25 \\
\hline 9 Artigos do vestuário e acessórios & 0 & 11 & 476 & 487 & 0,66 & 20 \\
\hline 10 Artefatos de couro e calçados & 0 & 1 & 232 & 233 & 0,32 & 34 \\
\hline $\begin{array}{l}11 \text { Produtos de madeira - exclusive } \\
\text { móveis }\end{array}$ & 0 & 15 & 72 & 88 & 0,12 & 45 \\
\hline 12 Celulose e produtos de papel & 0 & 57 & 290 & 347 & 0,47 & 30 \\
\hline 13 Jornais, revistas, discos & 0 & 121 & 309 & 430 & 0,59 & 24 \\
\hline 14 Produtos químicos & 0 & 339 & 384 & 723 & 0,99 & 14 \\
\hline $\begin{array}{l}15 \text { Fabricação de resina e elastô- } \\
\text { meros }\end{array}$ & 0 & 49 & 114 & 163 & 0,22 & 39 \\
\hline 16 Produtos farmacêuticos & 0 & 5 & 348 & 353 & 0,48 & 29 \\
\hline 17 Defensivos agrícolas & 0 & 58 & 117 & 175 & 0,24 & 36 \\
\hline 18 Perfumaria, higiene e limpeza & 0 & 21 & 290 & 311 & 0,42 & 32 \\
\hline $\begin{array}{l}19 \text { Tintas, vernizes, esmaltes e } \\
\text { lacas }\end{array}$ & 0 & 12 & 47 & 59 & 0,08 & 48 \\
\hline $\begin{array}{l}20 \text { Produtos e preparados químicos } \\
\text { diversos }\end{array}$ & 0 & 84 & 86 & 171 & 0,23 & 37 \\
\hline 21 Artigos de borracha e plástico & 0 & 164 & 374 & 538 & 0,73 & 19 \\
\hline 22 Cimento & 0 & 41 & 23 & 63 & 0,09 & 47 \\
\hline $\begin{array}{l}23 \text { Outros produtos de minerais não } \\
\text { metálicos }\end{array}$ & 0 & 69 & 95 & 164 & 0,22 & 38 \\
\hline 24 Fabricação de aço e derivados & 0 & 159 & 213 & 372 & 0,51 & 27 \\
\hline $\begin{array}{l}25 \text { Metalurgia de metais não ferro- } \\
\text { sos }\end{array}$ & 0 & 131 & 79 & 210 & 0,29 & 35 \\
\hline $\begin{array}{l}26 \text { Produtos de metal - exclusive } \\
\text { máquinas e equipamentos }\end{array}$ & 0 & 321 & 239 & 561 & 0,76 & 17 \\
\hline $\begin{array}{l}27 \text { Máquinas e equipamentos, inclu- } \\
\text { sive manutenção e reparo }\end{array}$ & 0 & 208 & 135 & 343 & 0,47 & 31 \\
\hline
\end{tabular}


cont.

28 Eletrodomésticos

29 Máquinas para escritório e equipamentos de informática

30 Máquinas, aparelhos e materiais elétricos

31 Material eletrônico e equipamentos de comunicações

32 Aparelhos/instrumental médico-hospitalar, óptico

33 Automóveis, camionetas e utilitários

34 Caminhões e ônibus

35 Peças e acessórios para veículos automotores

36 Outros equipamentos de transporte

37 Móveis e produtos das indústrias diversas

38 Construção

39 Comércio

40 Transporte, armazenagem e correio

41 Serviços de informação

42 Intermediação financeira e seguros

43 Serviços imobiliários e aluguel

44 Serviços de manutenção e reparação

45 Serviços de alojamento e alimentação

46 Serviços prestados às empresas

47 Educação mercantil

48 Saúde mercantil

49 Serviços prestados às famílias e associativas

50 Serviços domésticos

51 Educação pública

52 Saúde pública

53 Administração pública e seguridade social

\begin{tabular}{l}
\hline Total \\
\hline Multiplicador do impacto energético \\
na produção do Brasil
\end{tabular}

Fonte: elaboração dos autores. 


\section{Anexo B}

Tabela 2 - Impacto direto, indireto e induzido de um aumento de $15,62 \%$ da demanda final do setor energético sobre o emprego dos setores da economia brasileira para o ano de 2015, com base em 2009

\begin{tabular}{|c|c|c|c|c|c|c|}
\hline \multirow{3}{*}{ Setores } & \multicolumn{6}{|c|}{ Emprego } \\
\hline & \multicolumn{4}{|c|}{ Impactos em números } & \multicolumn{2}{|c|}{$\begin{array}{l}\text { Distribuição dos } \\
\text { efeitos totais }\end{array}$} \\
\hline & Direto & Indireto & Induzido & Total & Percentual & Ordem \\
\hline $\begin{array}{l}1 \text { Agricultura, silvicultura, explo- } \\
\text { ração florestal }\end{array}$ & 0 & 55.472 & 91.605 & 147.077 & 16,67 & 1 \\
\hline 2 Pecuária e pesca & 0 & 2.707 & 42.613 & 45.320 & 5,14 & 7 \\
\hline 3 Energético & 29.046 & 13.435 & 4.553 & 47.034 & 5,33 & 6 \\
\hline 4 Minério de ferro & 0 & 18 & 23 & 41 & 0,00 & 52 \\
\hline 5 Outros da indústria extrativa & 0 & 533 & 642 & 1.175 & 0,13 & 33 \\
\hline 6 Alimentos e bebidas & 0 & 1.293 & 22.409 & 23.702 & 2,69 & 10 \\
\hline 7 Produtos do fumo & 0 & 0 & 180 & 180 & 0,02 & 48 \\
\hline 8 Têxteis & 0 & 507 & 8.952 & 9.459 & 1,07 & 17 \\
\hline $\begin{array}{l}9 \text { Artigos do vestuário e aces- } \\
\text { sórios }\end{array}$ & 0 & 507 & 21.937 & 22.445 & 2,54 & 12 \\
\hline 10 Artefatos de couro e calçados & 0 & 17 & 5949 & 5.966 & 0,68 & 22 \\
\hline $\begin{array}{l}11 \text { Produtos de madeira - exclusi- } \\
\text { ve móveis }\end{array}$ & 0 & 367 & 1723 & 2.089 & 0,24 & 30 \\
\hline 12 Celulose e produtos de papel & 0 & 258 & 1316 & 1.574 & 0,18 & 31 \\
\hline 13 Jornais, revistas, discos & 0 & 1.230 & 3.154 & 4.383 & 0,50 & 23 \\
\hline 14 Produtos químicos & 0 & 514 & 582 & 1.096 & 0,12 & 34 \\
\hline $\begin{array}{l}15 \text { Fabricação de resina e elas- } \\
\text { tômeros }\end{array}$ & 0 & 61 & 140 & 201 & 0,02 & 47 \\
\hline 16 Produtos farmacêuticos & 0 & 15 & 1.035 & 1.050 & 0,12 & 35 \\
\hline 17 Defensivos agrícolas & 0 & 83 & 167 & 250 & 0,03 & 45 \\
\hline 18 Perfumaria, higiene e limpeza & 0 & 89 & 1.236 & 1.325 & 0,15 & 32 \\
\hline $\begin{array}{l}19 \text { Tintas, vernizes, esmaltes e } \\
\text { lacas }\end{array}$ & 0 & 34 & 137 & 171 & 0,02 & 49 \\
\hline $\begin{array}{l}20 \text { Produtos e preparados quími- } \\
\text { cos diversos }\end{array}$ & 0 & 460 & 473 & 932 & 0,11 & 36 \\
\hline 21 Artigos de borracha e plástico & 0 & 1.154 & 2.625 & 3.778 & 0,43 & 24 \\
\hline 22 Cimento & 0 & 60 & 33 & 93 & 0,01 & 51 \\
\hline $\begin{array}{l}23 \text { Outros produtos de minerais } \\
\text { não metálicos }\end{array}$ & 0 & 1.018 & 1.392 & 2.409 & 0,27 & 28 \\
\hline 24 Fabricação de aço e derivados & 0 & 276 & 370 & 646 & 0,07 & 39 \\
\hline $\begin{array}{l}25 \text { Metalurgia de metais não } \\
\text { ferrosos }\end{array}$ & 0 & 501 & 302 & 803 & 0,09 & 37 \\
\hline $\begin{array}{l}26 \text { Produtos de metal - exclusive } \\
\text { máquinas e equipamentos }\end{array}$ & 0 & 3.811 & 2.841 & 6.652 & 0,75 & 21 \\
\hline $\begin{array}{l}27 \text { Máquinas e equipamentos, in- } \\
\text { clusive manutenção e reparo }\end{array}$ & 0 & 1.379 & 893 & 2.272 & 0,26 & 29 \\
\hline
\end{tabular}


cont.

28 Eletrodomésticos

29 Máquinas para escritório e equipamentos de informática

30 Máquinas, aparelhos e materiais elétricos

31 Material eletrônico e equipamentos de comunicações

32 Aparelhos/instrumental médico-hospitalar, óptico

33 Automóveis, camionetas e utilitários

34 Caminhões e ônibus

35 Peças e acessórios para veículos automotores

36 Outros equipamentos de transporte

37 Móveis e produtos das indústrias diversas

38 Construção

39 Comércio

40 Transporte, armazenagem e correio

41 Serviços de informação

42 Intermediação financeira e seguros

43 Serviços imobiliários e aluguel

44 Serviços de manutenção e reparação

45 Serviços de alojamento e alimentação

46 Serviços prestados às empresas

47 Educação mercantil

48 Saúde mercantil

49 Serviços prestados às famílias e associativas

50 Serviços domésticos

51 Educação pública

52 Saúde pública

53 Administração pública e seguridade social

\begin{tabular}{l|r}
\hline Total & 29.04 \\
\hline $\begin{array}{l}\text { Multiplicador do impacto energé- } \\
\text { tico no emprego do Brasil }\end{array}$ & 1,00
\end{tabular}

Fonte: elaboração dos autores.

\begin{tabular}{|c|c|c|c|}
\hline 6 & 597 & 604 & 0,07 \\
\hline 19 & 117 & 136 & 0,02 \\
\hline 2.056 & 977 & 3.033 & 0,34 \\
\hline 66 & 375 & 441 & 0,05 \\
\hline 69 & 649 & 718 & 0,08 \\
\hline 2 & 599 & 601 & 0,07 \\
\hline 4 & 17 & 21 & 0,00 \\
\hline 593 & 1.873 & 2.466 & 0,28 \\
\hline 30 & 401 & 431 & 0,05 \\
\hline 274 & 7.223 & 7.497 & 0,85 \\
\hline 4.865 & 4.134 & 8.999 & 1,02 \\
\hline 24.305 & 121.935 & 146.241 & 16,58 \\
\hline 19.688 & 31.949 & 51.637 & 5,85 \\
\hline 6.107 & 13.417 & 19.524 & 2,21 \\
\hline 1.738 & 7.819 & 9.557 & 1,08 \\
\hline 1.493 & 6.947 & 8.439 & 0,96 \\
\hline 3.278 & 19.790 & 23.069 & 2,61 \\
\hline 1.761 & 37.618 & 39.378 & 4,46 \\
\hline 34.312 & 31.128 & 65.441 & 7,42 \\
\hline 654 & 16.820 & 17.474 & 1,98 \\
\hline 657 & 17.835 & 18.492 & 2,10 \\
\hline 6.195 & 31.762 & 37.957 & 4,30 \\
\hline 0 & 84.118 & 84.118 & 9,53 \\
\hline 84 & 139 & 223 & 0,03 \\
\hline 0 & 351 & 351 & 0,04 \\
\hline 1.502 & 1.755 & 3.258 & 0,37 \\
\hline 195.556 & 657.626 & 882.228 & 100,00 \\
\hline 6,73 & 22,64 & 30,37 & \\
\hline
\end{tabular}

53

27

43

20

8

2

5

13

16

9

11

8

4

15

4

9

4

25 


\section{Anexo C}

Tabela 3 - Impacto direto, indireto e induzido de um aumento de $15,62 \%$ da demanda final do setor energético sobre os salários dos setores da economia brasileira para o ano de 2015, com base em 2009

\begin{tabular}{|c|c|c|c|c|c|c|}
\hline \multirow{3}{*}{ Setores } & \multicolumn{6}{|c|}{ Salários } \\
\hline & \multicolumn{4}{|c|}{ Impactos em milhões de R\$ } & \multicolumn{2}{|c|}{$\begin{array}{l}\text { Distribuição dos } \\
\text { efeitos totais }\end{array}$} \\
\hline & Direto & Indireto & Induzido & Total & Percentual & Ordem \\
\hline $\begin{array}{l}1 \text { Agricultura, silvicultura, explora- } \\
\text { ção florestal }\end{array}$ & 0 & 123 & 203 & 325 & 3,33 & 8 \\
\hline 2 Pecuária e pesca & 0 & 10 & 158 & 168 & 1,72 & 14 \\
\hline 3 Energético & 1.468 & 679 & 230 & 2.377 & 24,32 & 1 \\
\hline 4 Minério de ferro & 0 & 1 & 1 & 2 & 0,02 & 52 \\
\hline 5 Outros da indústria extrativa & 0 & 7 & 8 & 15 & 0,15 & 42 \\
\hline 6 Alimentos e bebidas & 0 & 17 & 294 & 311 & 3,18 & 9 \\
\hline 7 Produtos do fumo & 0 & 0 & 8 & 8 & 0,08 & 47 \\
\hline 8 Têxteis & 0 & 3 & 56 & 59 & 0,61 & 26 \\
\hline 9 Artigos do vestuário e acessórios & 0 & 2 & 97 & 99 & 1,01 & 16 \\
\hline 10 Artefatos de couro e calçados & 0 & 0 & 52 & 52 & 0,53 & 28 \\
\hline $\begin{array}{l}11 \text { Produtos de madeira - exclusive } \\
\text { móveis }\end{array}$ & 0 & 3 & 14 & 16 & 0,17 & 39 \\
\hline 12 Celulose e produtos de papel & 0 & 7 & 37 & 44 & 0,45 & 32 \\
\hline 13 Jornais, revistas, discos & 0 & 21 & 53 & 73 & 0,75 & 23 \\
\hline 14 Produtos químicos & 0 & 23 & 26 & 48 & 0,49 & 30 \\
\hline $\begin{array}{l}15 \text { Fabricação de resina e elastô- } \\
\text { meros }\end{array}$ & 0 & 3 & 7 & 11 & 0,11 & 46 \\
\hline 16 Produtos farmacêuticos & 0 & 1 & 49 & 50 & 0,51 & 29 \\
\hline 17 Defensivos agrícolas & 0 & 5 & 10 & 15 & 0,16 & 41 \\
\hline 18 Perfumaria, higiene e limpeza & 0 & 2 & 28 & 30 & 0,30 & 34 \\
\hline 19 Tintas, vernizes, esmaltes e lacas & 0 & 2 & 6 & 8 & 0,08 & 48 \\
\hline $\begin{array}{l}20 \text { Produtos e preparados químicos } \\
\text { diversos }\end{array}$ & 0 & 10 & 10 & 20 & 0,21 & 37 \\
\hline 21 Artigos de borracha e plástico & 0 & 24 & 55 & 79 & 0,81 & 21 \\
\hline 22 Cimento & 0 & 3 & 2 & 4 & 0,04 & 51 \\
\hline $\begin{array}{l}23 \text { Outros produtos de minerais não } \\
\text { metálicos }\end{array}$ & 0 & 12 & 17 & 29 & 0,29 & 35 \\
\hline 24 Fabricação de aço e derivados & 0 & 14 & 19 & 32 & 0,33 & 33 \\
\hline 25 Metalurgia de metais não ferrosos & 0 & 14 & 8 & 22 & 0,23 & 36 \\
\hline $\begin{array}{l}26 \text { Produtos de metal - exclusive } \\
\text { máquinas e equipamentos }\end{array}$ & 0 & 54 & 40 & 94 & 0,96 & 19 \\
\hline $\begin{array}{l}27 \text { Máquinas e equipamentos, inclu- } \\
\text { sive manutenção e reparo }\end{array}$ & 0 & 37 & 24 & 60 & 0,62 & 25 \\
\hline 28 Eletrodomésticos & 0 & 0 & 18 & 18 & 0,18 & 38 \\
\hline
\end{tabular}


cont.

29 Máquinas para escritório e equipamentos de informática

30 Máquinas, aparelhos e materiais elétricos

31 Material eletrônico e equipamentos de comunicações

32 Aparelhos/instrumental médico-hospitalar, óptico

33 Automóveis, camionetas e utilitários

34 Caminhões e ônibus

35 Peças e acessórios para veículos automotores

36 Outros equipamentos de transporte

37 Móveis e produtos das indústrias diversas

38 Construção

39 Comércio

40 Transporte, armazenagem e correio

41 Serviços de informação

42 Intermediação financeira e seguros

43 Serviços imobiliários e aluguel

44 Serviços de manutenção e reparação

45 Serviços de alojamento e alimentação

46 Serviços prestados às empresas

47 Educação mercantil

48 Saúde mercantil

49 Serviços prestados às famílias e associativas

50 Serviços domésticos

51 Educação pública

52 Saúde pública

53 Administração pública e seguridade social

Total no salário do Brasil

\begin{tabular}{|c|c|c|c|c|c|}
\hline 0 & 1 & 4 & 4 & 0,05 & 50 \\
\hline 0 & 55 & 26 & 82 & 0,84 & 20 \\
\hline 0 & 2 & 11 & 13 & 0,14 & 44 \\
\hline 0 & 1 & 12 & 13 & 0,14 & 43 \\
\hline 0 & 0 & 46 & 46 & 0,47 & 31 \\
\hline 0 & 0 & 1 & 2 & 0,02 & 53 \\
\hline 0 & 18 & 57 & 76 & 0,77 & 22 \\
\hline 0 & 1 & 15 & 16 & 0,16 & 40 \\
\hline 0 & 2 & 52 & 54 & 0,55 & 27 \\
\hline 0 & 35 & 30 & 65 & 0,67 & 24 \\
\hline 0 & 188 & 944 & 1.132 & 11,58 & 2 \\
\hline 0 & 261 & 424 & 686 & 7,02 & 4 \\
\hline 0 & 102 & 225 & 327 & 3,35 & 7 \\
\hline 0 & 105 & 471 & 576 & 5,90 & 5 \\
\hline 0 & 17 & 79 & 96 & 0,99 & 17 \\
\hline 0 & 13 & 81 & 94 & 0,96 & 18 \\
\hline 0 & 9 & 187 & 195 & 2,00 & 13 \\
\hline 0 & 438 & 397 & 835 & 8,54 & 3 \\
\hline 0 & 11 & 279 & 290 & 2,97 & 10 \\
\hline 0 & 10 & 265 & 275 & 2,82 & 12 \\
\hline 0 & 46 & 236 & 281 & 2,88 & 11 \\
\hline 0 & 0 & 414 & 414 & 4,23 & 6 \\
\hline 0 & 2 & 3 & 5 & 0,05 & 49 \\
\hline 0 & 0 & 11 & 11 & 0,12 & 45 \\
\hline 0 & 51 & 60 & 110 & 1,13 & 15 \\
\hline 1.468 & 2.444 & 5.860 & 9.772 & 100,00 & \\
\hline 1,00 & 1,66 & 3,99 & 6,66 & & \\
\hline
\end{tabular}

Fonte: elaboração dos autores. 